
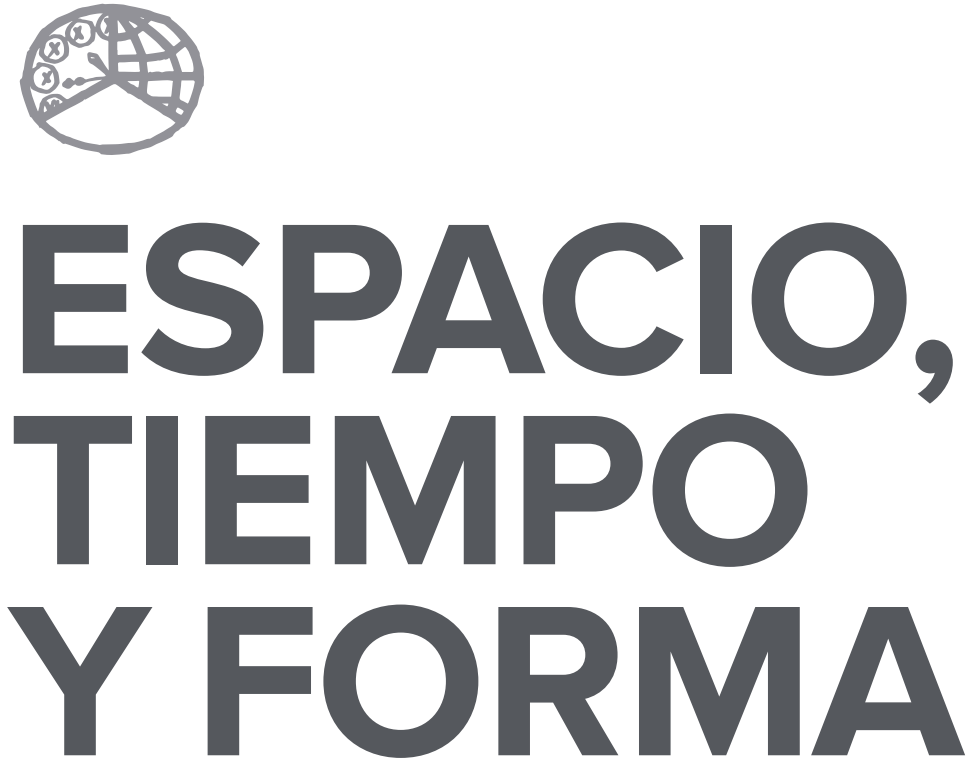

AÑO 2020

ISSN 0214-9745

E-ISSN 2340-1362

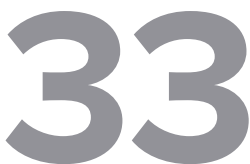

SERIE III HISTORIA MEDIEVAL

REVISTA DE LA FACULTAD DE GEOGRAFÍA E HISTORIA 



\section{ARTÍCULOS · ARTICLES}





\title{
ENTRE SERVICIO REGIO Y ESTRATEGIA PERSONAL: LOS CONTINOS DE VALLADOLID (1480-1525)
}

\section{BETWEEN ROYAL SERVICE AND \\ PERSONAL STRATEGY: THE CONTINOS OF VALLADOLID (1480-1525)}

\author{
María Francisca García Alcázar y María Ángeles Martín Romera²
}

Recepción: 2019/03/14 C Comunicación de observaciones de evaluadores: 2019/04/29 .

Aceptación: 2019/05/07

DOI: http://dx.doi.org/10.5944/etfiii.33.2020.24052

\section{Resumen}

El presente artículo aborda el estudio de los continos reales incidiendo tanto en su carácter de oficio regio, como elemento clave para entender el desarrollo de la figura del oficial en la época premoderna, como en el valor que el cargo tuvo en las estrategias familiares y personales de aquellos que lo ejercieron. Para ello se combina la visión conjunta del reino que proporcionan los archivos reales con un estudio concreto de la oligarquía de Valladolid. Este último estudio se apoya a su vez en un doble enfoque: por un lado la prosopografía de las élites vallisoletanas y, por otro, el análisis de sus redes sociales. El resultado es una aproximación a la integración real de estos servidores regios en la sociedad local que permite comprender el papel que este cargo pudo tener en sus trayectorias personales, así como el interés de los monarcas por nombrar como continos a determinados individuos. Como oficio, su flexibilidad e indefinición permitía variar los servicios y condiciones en función de las necesidades tanto de la monarquía como de los sujetos implicados.

Palabras clave

Continos; Castilla; oficiales regios; servicio; ciudades; oligarquía.

\footnotetext{
1. Doctoranda. Universidad Complutense de Madrid. C.e.: mfgalcazar@ucm.es

2. Marie Sklodowska-Curie Fellow. University College London. C.e.: m.romera@ucl.ac.uk

Este trabajo se ha realizado en el marco del proyecto CIUCASDIN (HAR2017-82983-P), financiado por el Ministerio de Ciencia, Innovación y Universidades, y dirigido desde la UCM.
} 


\begin{abstract}
This article analyses the royal continos by addressing both the nature of the office as a key element in the development of officialdom in the pre-Modern era, and the way in which holding the position of contino affected personal and family strategies. This study includes a global perspective on continos in the kingdom by exploring royal documentation, as well as a case study of the oligarchy of Valladolid. This specific case is based on a double approach: on the one hand, the prosopography of urban elites, and on the other hand, the analysis of their social networks. As a result, it combines an analysis of the impact of the office on these royal servants' personal trajectories and integration in a local context, as well as the king's rationality behind the appointment of these officials. The contino office was particularly flexible and its indefinite nature allowed a degree of variability in the service and conditions based on the needs both of the monarchy and of those individuals involved.
\end{abstract}

\title{
Keywords
}

Continos; Castile; Royal Officers; Service; Cities; Oligarchy. 


\section{INTRODUCCIÓN}

Desde los trabajos de Max Weber, que a pesar de las numerosas críticas y revisiones continúan siendo un referente imprescindible ${ }^{3}$, el concepto de oficio es uno de los grandes temas de la historiografía. En el caso castellano la discusión en torno al significado de oficial ha tenido un protagonismo destacado en los estudios institucionales de los historiadores del derecho ${ }^{4}$, pero al mismo tiempo, bien sea como problema central o colateral, está presente en muchos de los grandes debates de la historiografía hispánica como la justicia distributiva, la venalidad, el clientelismo, el servicio, los estudios sobre corrupción, la polémica disputa entre mérito o sangre, o los orígenes del Estado, entre otros 5 .

Mientras que las definiciones institucionales del concepto de oficio parecen relativamente claras, la práctica resulta mucho más controvertida, especialmente en los casos de aquellos oficios para los que no contamos con una reglamentación o ni tan siquiera con unos patrones claros. En este contexto los oficios bajomedievales, aunque presentan una dificultad aun mayor por la falta de fuentes, se corresponden también con un período clave en el desarrollo de la oficialidad en toda Europa. Miguel Ángel Ladero Quesada ya apuntó acertadamente que en

3. Weber, Max.: Economía y Sociedad. México, FCE, 1974. Las ideas weberianas del oficial como idealtypus se integran en las discusiones en torno al surgimiento de los oficiales en época medieval en numerosos estudios. Por ejemplo en BISson, Thomas N.: La crisis del siglo XIl: el poder, la nobleza y los orígenes de la gobernación europea. Barcelona, Crítica, 2010; o en PARAVICINI, Werner.: «Administrateurs professionnels et princes dilettantes. Remarques sur un problème de sociologie administrative à la fin du moyen âge», en PARAVICINI, Werner y WERNER, Karl Ferdinand (eds.): Histoire comparée de l'administration (IVe-XVIIIe siècles). Actes du XIVe colloque historique franco-allemand. Tours, 27 mars - $1^{e r}$ avril 1977. München, Artemis Verlag, 1980, pp. 168-181.

4. Sin pretender un análisis exhaustivo de la ingente bibliografía que se ha ocupado de estos temas, caben señalar los estudios de Luis García de Valdeavellano y Benjamín González Alonso, además de los trabajos de conjunto de García Marín. Entre otros, véanse GARCía de VALDEAVELLANO, Luis: Curso de Historia de las instituciones españolas: de los orígenes al final de la Edad Media. Madrid. Alianza, 1986 (primera edición 1968); GonzÁlezz Alonso, Benjamín: El corregidor castellano (1348-1808). Madrid, Instituto de Estudios Administrativos, 1970; GARcía MARín, José María: La burocracia castellana bajo los Austrias, Madrid, Instituto Nacional de Administración Pública, 1986; García Marín, José María: El oficio público en Castilla durante la Baja Edad Media. Alcalá de Henares, Instituto Nacional de Administración Pública, 1987.

5. Sería imposible citar todos los trabajos reseñables que abordan estos temas. Nos remitimos a una serie de obras colectivas (desde algunos trabajos de los años noventa propiciados por el interés en el surgimiento del Estado, hasta las perspectivas más recientes en torno a los oficiales) que a su vez proporcionan la bibliografía más destacada respecto a los temas que abordan: Descimon, Robert, SCHAUB, Jean-Frédéric y VINCENT, Bernard (eds.): Les Figures de l'administrateur. Institutions, réseaux, pouvoirs en Espagne, en France et au Portugal, XVI-XIX siècle. París, Éditions de l'École des Hautes Études en Sciences Sociales, 1997; REINHARD, Wolfgang (comp.): Las élites del poder y la construcción del estado. Madrid, F.C.E. de España, 1997; VV.AA.: Les serviteurs de l'État au Moyen Âge, Actes du XXIXe congrès de la SHMESP (Pau, 1998), París, Publications de la Sorbonne, 1999; PARDo Molero Juan Francisco, y Lomas Cortés, Manuel (coords.): Oficiales reales: los ministros de la Monarquía Católica, siglos XVI y XVII. Valencia, Universitat de València, 2012; Esteban Estríngana, Alicia (coord.): Servir al rey en la Monarquía de los Austrias. Medios, fines y logros del servicio al soberano en los siglos XVI y XVII. Madrid, Sílex, 2012; StumPF, Roberta, ChaturveduLA, Nandini (coords.): Cargos e ofícios nas monarquias ibéricas: provimento, controlo e venalidade (séculos XVII e XVIII). Lisboa, CHAM, 2012; PONCE LeIVA, Pilar y Andújar CASTILLO, Francisco (coords.): Mérito, venalidad y corrupción en España y América: siglos XVII y XVIII, Valencia, Albatros, 2016; Brendecke, Arndt y Martín Romera, Ma Ángeles (coords.): «El «habitus» del oficial real: ideal, percepción y ejercicio del cargo en la monarquía hispánica (siglos XV-XVIII)», Studia Historica. Historia Moderna, 39-1 (2017), pp. 23-51. 
este contexto los continos reales personificaban un estadío en transición entre un modelo de servicio personal y el desarrollo de un cuerpo de funcionarios ${ }^{6}$.

Los continos reales castellanos eran servidores regios, dependientes de la Casa Real, con un perfil funcional indefinido que permitía a los reyes utilizarlos según las necesidades que la coyuntura de cada momento requería, por ello los servicios que prestaban podían abarcar todo tipo de tareas político administrativas o bien realizarse dentro del ejército real, de acuerdo a su procedencia social.

El cargo de contino en Castilla, que hasta ahora no ha merecido tanta atención como cabría esperar ${ }^{7}$, goza de una serie de cualidades que le convierten en asunto privilegiado para analizar el teórico tránsito de un tipo de oficial bajomedieval en una relación personal con el rey a un oficial claramente reglamentado con atribuciones y retribuciones estipuladas y, en teoría, al servicio de una administración en proceso de definición.

De hecho, como se expondrá a lo largo de este trabajo, sería más adecuado hablar no tanto de un tránsito entre uno y otro modelo, sino de la existencia de forma simultánea, de diferentes tendencias a la hora de determinar el carácter del oficio de contino. Es este un cargo que, justamente por su plasticidad y por carecer de un reglamento concreto, se presta a que los reyes experimenten distintos tipos de soluciones y a que los individuos lo utilicen de modo muy diverso en sus estrategias de ascenso familiares y personales. Por el momento en el que la figura de contino se asienta y se regulariza y por el mencionado carácter flexible de la misma, no cabe duda de que los continos castellanos tuvieron un papel clave para el desarrollo de la figura de oficial en el territorio hispánico, así como las distintas dinámicas que entraron en juego en la oscilante definición de estos y otros oficios en los momentos inaugurales de los Estados premodernos.

Metodológicamente el artículo combina la visión conjunta del reino con el estudio pormenorizado de los continos de uno de los centros urbanos más importantes de Castilla y con especial presencia de continos, la villa de Valladolid. Una de las mayores dificultades a la hora de analizar la figura de los continos reales desde un punto de vista social y en su contexto de origen es la procedencia de la

6. Ladero Quesada, Miguel Ángel: La España de los Reyes Católicos. Madrid, Alianza Editorial, 1999, p. 161.

7. Entre los trabajos consagrados a esta figura cabe destacar los siguientes: MONTERO TEJADA, Rosa Mª: «Monarquía y gobierno concejil: continos reales en las ciudades castellanas a comienzos de la Edad Moderna», en BERNARDo ARES, José Manuel (Coord.), La Administración municipal en la Edad Moderna. Actas V Reunión científica de la Asociación Española de Historia Moderna, Vol. 2, Cádiz, 1999, pp. 577-590; y «Los continos 'hombres de armas' de la Casa Real castellana (1495-1516)», Boletín de la Real Academia de la Historia, 198-I (2001), pp. 103-130, RodríGuez López, Inés: «Continos de Aragón en la empresa colombina» en ARmILLAS VICENTE, José Antonio, VII Congreso Internacional de Historia de América: ponencias y comunicaciones (Zaragoza del 2 al 6 de julio de 1996), Zaragoza, 1998, pp. 651-664; Los continos de la Casa Real durante el reinado de los Reyes Católicos (Tesis doctoral inédita), Departamento de Derecho Penal e Historia y Teoría del Derecho, Universidad de Valladolid, 2006; SZASZDI LEÓN-BORJA, István: «Los continos de don Cristóbal Colón», Espacio, Tiempo y Forma, Serie III Historia Medieval, 13 (2000), pp. 397-420; GAMERo IGEA, Germán: «Entre Castilla y Aragón. Los continos en el reinado de Fernando el Católico», en CarvajaL, David, Víctores, Imanol, AÑíbarro, Javier (eds.): Poder, Fisco y Mercado en las ciudades de la Península Ibérica (siglos XIV-XVI), Valladolid, Castilla Ediciones, 2016, pp. 193-208. En particular, acerca del estado de la cuestión véase GARCíA ALCÁZAR, M ${ }^{a}$ Francisca: «Los continos reales de Castilla durante la baja Edad Media. Estado de la Cuestión», Espacio, Tiempo y Forma. Serie III. Historia Medieval, 30 (2017), pp. 335-358. 
documentación. Los archivos reales, en concreto el Archivo General de Simancas en sus secciones de la Escribanía Mayor de Rentas, que contiene los libros de continos, y el Registro General del Sello, aportan escasos datos biográficos para su estudio. Esta documentación solo permite identificar a los continos reales y, en ocasiones, conocer de dónde eran vecinos y su filiación familiar (hijos de, hermanos de, sobrinos de...). La combinación de esta documentación con un estudio concreto sobre la oligarquía de Valladolid, donde el trabajo prosopográfico fue complementado con el Análisis de Redes Sociales ${ }^{8}$, permite conjugar dos valiosas fuentes de conocimiento en dos ámbitos complementarios: corte y ciudad. El resultado es una aproximación a la integración real de estos servidores regios en la sociedad local que permite comprender el papel que este cargo pudo tener en las trayectorias personales de quienes lo ejercían, así como el interés de los monarcas por nombrar como continos a determinados individuos.

Este estudio contrastado ha llevado a la conclusión de que ser contino era una estrategia más dentro de un conjunto de recursos a los que acudían las familias con una cierta posición o con aspiraciones a ascender; recursos que a menudo se consideraban interconectados y complementarios. Por ello el cargo no significó lo mismo en todo momento y para todos los oficiales, sino que dependió de diversas coyunturas que afectaron tanto al contenido del oficio (las tareas y la asignación económica) como a su valor social y las opciones de ascenso que proporcionaba. En consecuencia, en lugar de hablar del oficio de contino en abstracto, se propone aquí su estudio en relación a tres ejes principales. El primer eje sería la coyuntura del reino y el interés regio, que favorecieron un diseño del cuerpo de continos a imagen y semejanza de las necesidades que Castilla fue enfrentando, desde la guerra de Granada a las tensiones dinásticas y posteriormente la revuelta de las Comunidades. El segundo eje sería el tipo de servicio que los continos realizaban, el cual estaría relacionado con sus emolumentos, su perfil social y su estatus. Por último, un tercer eje tratado es el de los distintos factores relativos a la integración de los continos en las oligarquías locales al objeto de valorar su posición respecto al gobierno urbano. Estos factores interactuaban con el oficio de contino y determinaron el papel que este cargo jugó en las estrategias de ascenso social y de cohesión entre las filas de las élites urbanas.

Estos tres ejes fueron determinantes en el caso de Valladolid a la hora de condicionar las trayectorias y el tratamiento de los continos en la villa, así como el valor sociopolítico del cargo, y es de suponer que tendrían un peso análogo en la situación de los continos de otras ciudades castellanas. En la medida en que dichos ejes permiten distintas constelaciones hay que entender los resultados de este estudio como tendencias que dependen del modo en que los distintos

8. Martín Romera, Ma Ángeles: Redes de poder: las relaciones sociales de la oligarquía de Valladolid (1450-1520). Madrid, CSIC, 2019. El libro es una versión completada y actualizada de Las redes sociales de la oligarquía de la villa de Valladolid, (1450-1520), tesis leída en la Universidad Complutense de Madrid, 2012. 
factores interactuaron en cada caso y cuya validez es susceptible de futuras comprobaciones contrastando este modelo con otros ejemplos fuera de Valladolid.

Finalmente, el recorrido a lo largo de estos tres ejes, nos permite cuestionar cuáles son los rasgos que dieron forma a la oficialidad bajomedieval y altomoderna en Castilla.

\section{LA COYUNTURA DEL REINO Y EL INTERÉS REGIO}

Aunque el momento exacto en que aparece el oficio de contino es incierto, ya durante el reinado de Enrique IV existían continos cuya función exacta se desconoce $^{9}$. El oficio adquiere su pleno desarrollo durante el reinado de los Reyes Católicos y especialmente a partir de las Cortes de Toledo de I48o, apareciendo el asiento de continos y la nómina en I48I, lo que en la práctica los definía como un cuerpo de oficiales de la Casa Real y al servicio de la Corona.

Si durante la plena Edad Media los reyes habían recurrido a los privilegios para asegurar el apoyo de las élites urbanas en un juego de doble legitimación -de la Corona a la caballería urbana y viceversa- ${ }^{\mathrm{I}}$, el desarrollo de un aparato burocrático a través de la multiplicación de oficiales va a permitir utilizar los cargos unipersonales para fidelizar a estas élites. Dentro de esta estrategia el desarrollo de los continos supuso casi una revolución, tanto por su flexibilidad como por el número inicialmente ilimitado de personas que permitía «acostar/asociar» a la Corona. Mientras que las procuraciones afectaban a un número extremadamente reducido de dirigentes urbanos y los regimientos, aunque mediatizados, respondían a las propias dinámicas del gobierno urbano (especialmente con la extensión de la hereditariedad del cargo $)^{\mathrm{II}}$, la designación de numerosos continos proporcionaba una forma ulterior de ligar las oligarquías urbanas al servicio de los monarcas con la ventaja de que se podía aplicar a un número variable de servidores, sujetos a las necesidades puntuales de la Corona.

Esto se produjo a través de dos tendencias complementarias. Por un lado, los reyes designaban a sus continos como nuevos regidores aprovechando las vacantes

9. García Alcázar, Ma Francisca: op. cit. p. 344.

10. Asenjo GonzÁlez, María: «Fiscalidad regia y sociedad en los concejos en la Extremadura castellano-oriental durante el reinado de Alfonso X», Homenaje al profesor Juan Torres Fontes, Murcia, Universidad de Murcia, 1987, pp. 69-84. Monsalvo ANTÓN, José María: «Transformaciones sociales y relaciones de poder en los concejos de frontera, siglos XI-XIII. Aldeanos, vecinos y caballeros en las instituciones municipales», en PASTOR, Reyna (comp.), Relaciones de poder, de producción y parentesco en la Edad Media y Moderna. Aproximación a su estudio. Madrid, CSIC, 1990, pp. 109-170. Ladero Quesada, Miguel Ángel: «Monarquía y ciudades de realengo en Castilla. Siglos XII al XV», Anuario de Estudios medievales, 24 (1994), pp. 719-774. González JIMÉnez, Manuel: Alfonso X el Sabio. Barcelona, 2004, p. 158. Asenjo GonZÁLEZ, María: «La aristocratización política en Castilla. El proceso de participación urbana (1252- 1520)», en Nieto SoriA, José Manuel (dir.), La monarquía como conflicto en la corona castellano-leonesa (c. 1230-1504), Madrid, Sílex, 2006, pp. 133-196.

11. TOMÁS Y VALIENTE, Francisco: «Origen bajomedieval de la patrimonialización y la enajenación de oficios públicos en Castilla», Actas del I Symposium de Historia de la Administración. Madrid, I.E.A, 1970, pp. 123-160. 
o las renunciaciones dudosas en distintos gobiernos urbanos de Castilla. Por otro, los regidores de las ciudades son incorporados como continos, ligándolos así directamente al servicio de la Corona y permitiendo una mayor mediatización de las políticas urbanas ${ }^{\mathrm{I2}}$. Por ejemplo, en I483 los reyes toman por contino con una quitación de 40.000 maravedís a Juan de Herrera, quien ya entonces es identificado en el asiento como regidor de Valladolid. Tanto el cargo de regidor, como el de contino, pasarán de padre a hijo, primero a Jorge de Herrera y posteriormente al hijo de Jorge ${ }^{\mathrm{I} 3}$. Llamado como su abuelo, Juan de Herrera es recibido por el emperador y la reina Juana en 1523 aunque los primeros pagos se producen en 1526 y de forma relativamente continua hasta $\mathrm{I} 542$. El cargo, con el servicio aparejado a los reyes, se presenta entonces como un rasgo definitorio más del linaje de los Herrera, tal y como lo era el oficio de regidor.

En los primeros tiempos del reinado de los Reyes Católicos la figura de los continos reales sirvió tanto para dar salida a las aspiraciones de las oligarquías urbanas como para que la Corona atrajera hacia sí las lealtades que necesitaba tras la guerra civil y, en definitiva, integrar a distintas fuerzas sociales del reino dentro de su ámbito de poder e influencia ${ }^{14}$. Los monarcas se sirvieron de los continos, como servidores leales a la Corona, para asentar su presencia en todo el reino y así los encontramos participando activamente en la guerra de Granada y su posterior repoblación, en la conquista de Canarias, en el ámbito urbano enviados como agentes regios y/o corregidores, en el núcleo de la formación del nuevo ejército real, así como alcaides de fortalezas, etc. A inicios del siglo $\mathrm{XVI}$, las sucesivas muertes de los herederos de la Corona y la llegada de Felipe y Juana en enero de 1502 como príncipes de Asturias, convierte a las élites urbanas en piezas a atraer a las distintas facciones que se iban conformando. Si bien los continos siguen acometiendo funciones similares al periodo anterior, el cargo se muestra como una útil herramienta para asegurar fidelidades en este nuevo tablero político.

12. Esta tendencia ya fue señalada por Rodríguez LóPEZ, Inés: Los continos de la Casa Real... pp. 304-353; y recogida por García AlCÁZAR, Ma Francisca: op. cit. p. 341.

13. Archivo General de Simancas (AGS), Escribanía Mayor de Rentas (EMR), CONTINOS, Leg.4. Distintos aspectos de las vidas de las familias e individuos vallisoletanos aquí nombrados aparecen en otros trabajos sobre la ciudad, especialmente Rucquol, Adeline: Valladolid en la Edad Media. Valladolid, Junta de Castilla y León, Consejería de Educación y Cultura, 1997; BenNasSAR, Bartolomé: Valladolid en el Siglo de Oro. Una ciudad de Castilla y su entorno agrario en el siglo XVI. Valladolid, Ámbito, 1989; MARTín Romera, Ma Ángeles: Redes de poder..., pp. 60-90; y Majo TomÉ, Beatriz: Valladolid comunera: sociedad y conflictos en Valladolid en el tránsito de la Edad Media a la Moderna, Valladolid, Ayuntamiento de Valladolid, 2017. Aunque no fueron incorporadas en la publicación posterior, la tesis original de Martín Romera (2012) recoge además las biografías colectivas de las familias en el regimiento, incluida la familia Herrera aquí mencionada y muchas de las otras mencionadas más adelante. Para no caer en excesivas repeticiones, no se insistirá en adelante acerca de la presencia de estas familias en dichas publicaciones y tan solo se remitirá ocasionalmente a algunas de estas obras.

14. Martínez MilláN, José y Ezquerra Revilla, Ignacio, «La integración de las elites sociales en las monarquías dinásticas. Los continos» en Bravo LozAno, Jesús (ed.), Espacios de poder: Cortes, ciudades y villas (S. XVI-XVIII), Madrid, J. Bravo, 2002, pp. 339-380. 
El asiento de García de Alcocer de 1502 parece responder a esa intención de atraer a las élites ciudadanas a la facción real que representaba Fernando el Católico ${ }^{15}$. En 28 de agosto de 1506 es el rey Felipe el que le recibe como contino con la misma intención de atraer hacia sí a los dirigentes urbanos. En I506, una vez que las Cortes juraron a doña Juana como reina de Castilla, a don Felipe como su legítimo esposo y al príncipe Carlos como heredero, Felipe buscó ganarse la adhesión política de las élites castellanas incorporando a su casa a numerosos castellanos $^{16}$, entre los que se incluyeron, a la luz de la documentación, muchos continos. García de Alcocer no sería el único asentado como contino en estas fechas: el disputado regidor Juan Niño de Castro fue asentado en I5O2 y luego también el 3I de agosto de 1506 ya por el rey Felipe; el 20 de agosto de 1506 era recibido Pedro de Montemayor, hijo del regidor Alonso de Montemayor; el regidor Francisco de León era recibido como contino en 1505 y Fernando de Illescas, hijo del licenciado Gonzalo González de Illescas del Consejo Real, tenía dos asientos, uno en 1503 y otro en $1505^{17}$. También Francisco de Mercado fue asentado el 3I de agosto de I506. El juego político que se pone en marcha entre I502 y I506 entre Fernando el Católico y Felipe el Hermoso queda reflejado en los asientos de continos que tienen lugar en este período.

Un momento decisivo se produjo tras la revuelta de las Comunidades. Después de la derrota de Villalar siguieron una serie de condenas y represalias que al poco tiempo se vieron suavizadas, optando Carlos $\mathrm{V}$ por una política de reconciliación. En el ámbito de los continos esta dinámica se hizo especialmente evidente a través de dos decisiones consecutivas. En primer lugar, el despido de una serie de continos que habían participado en las Comunidades y a los que se les retiraban sus quitaciones. En segundo lugar, el edicto de perdón posterior y, de forma más concreta en el aspecto más práctico, la especificación en los libros de continos de que se libraran las quitaciones del año de 1520 y/o I52I a una serie de oficiales sin exigir comprobaciones. Esta decisión incluía a continos readmitidos tras el perdón, pero la decisión de omitir las comprobaciones se extendía también al resto ${ }^{\mathrm{I}}$.

15. Desde la muerte del príncipe Don Juan en 1497, la reina Isabel dejó la política del reino en manos de Fernando con lo que el grupo de servidores que apoyaban a la reina perdió influencia en la corte en favor de los «fernandinos». Por otra parte, en 1502, Felipe y Juana llegaban a Castilla para jurar como herederos al trono y los sectores nobiliarios así como las élites que habían sido perjudicados por la facción «fernandina» iniciaban su acercamiento a los herederos con la intención de verse favorecidos una vez llegaran al trono. MARTínez MiLLÁN, José: «De la muerte del príncipe Juan al fallecimiento de Felipe el Hermoso (1497-1506)» en Martínez MilLán, José (dir.): La corte de Carlos V. Corte y Gobierno, Vol.1, Madrid, 2000, pp. 45-72.

16. Idem, pp. 63-72.

17. AGS, EMR, CONTINOS, Leg. 5-1 y 6 .

18. Entre los continos que fueron despedidos y luego readmitidos se encontraban Antonio de Carranza, Gonzalo Cerdán, Fernando de Illescas, Juan de Estrada, Francisco Tamayo y Juan de San Pedro. A todos ellos se les libraría su quitación de los años 1520 y 1521 sin pedirles información de su servicio ni residencia, exigencia que tampoco se haría efectiva para los continos Francisco de Mercado, don Francisco de Tovar y Juan de Tovar, que no habían sido despedidos. AGS, EMR, CONTINOS, Leg. 2, 3, 5-1, 6, 8, 9-1 y 9-2. 
Frente a continos que efectivamente sirvieron al rey durante las Comunidades (por ejemplo Alonso Niño de Castro $^{19}$ ), contamos con muchos otros casos que muestran que el rey decidió hacer tabula rasa sin distinguir entre aquellos fieles y aquellos que temporalmente se habían encontrado entre las filas rebeldes ${ }^{20}$. Sin duda un motivo era la dificultad de encontrar testimonios fidedignos y unívocos en el clima de desorden generado tras las Comunidades. Los cambios de bandos, las informaciones contradictorias respecto a lo acaecido, y la necesidad de suavizar los castigos iniciales que habían retirado la quitación a muchos de los continos, así como de fidelizar nuevamente a las oligarquías urbanas, aconsejaban readmitir a los continos previos y abonarles el pago de I520 y I52I sin exigir más pruebas, asumiendo su servicio a la Corona ${ }^{21}$.

Sin embargo, esta decisión no tiene un carácter tan solo coyuntural ya que en este mismo momento se manifiestan otras concesiones que muestran una tendencia mayor a aceptar una suerte de derechos adquiridos de los continos sobre el cargo y sus emolumentos, al margen de la realización de servicios específicos. Se trata de una cuestión de vital importancia para la definición de las condiciones de los oficios en el periodo altomoderno y que será retomada en el último apartado.

\section{III.EL TIPO DE SERVICIO PRESTADO POR LOS CONTINOS}

A grandes rasgos se pueden proponer dos tipos de servicio por parte de los continos reales. Un servicio de tipo militar y otro de gestión que incluía funciones ejecutivas y de gestión político-administrativa y económica. Entre los continos vallisoletanos, la mayoría prestaron un servicio de tipo militar que asimismo es el tipo de servicio que predomina entre los miembros del regimiento ${ }^{22}$.

Ejemplo de servicio de gestión económica es el del contino real Lope de León. La familia León tenía varias ramas en Valladolid en la segunda mitad del siglo XV. Una rama ocupó el regimiento vallisoletano durante el siglo XV hasta bien entrado el XVI, y otra el oficio de canciller del sello de Valladolid. Lope de León pertenece a esta última.

19. AGS, EMR, CONTINOS, Leg. 6.

20. Es el caso, por ejemplo, de Antonio Carranza, asentado como contino desde 1511, respecto al cual en 1521 se dice que se le pague 1521 sin pedirle residencia ni información de servicio (AGS, EMR, CONTINOS, Leg. 2).

21. Ejemplo de los testimonios contradictorios acerca de la actuación de estos oligarcas durante las Comunidades pueden hallarse en Martín Romera, Ma Ángeles: Redes de poder: ..., pp. 333-340.

22. GAMERo IGEA, Germán: op. cit., p. 202, sostiene que la función militar sería la función original de los continos y que esta prevaleció en Aragón. Las fuentes muestran que, aunque los Reyes Católicos recurrieron a continos gestores y ejecutores, la presencia de continos con funciones guerreras siguió siendo muy considerable también en Castilla al menos hasta las Comunidades. 
En abril de I447 Fernán González de León, amo del rey Enrique IV, renunció el oficio de canciller del sello del concejo de Valladolid en García de León ${ }^{23}$, padre de Lope de León y, en aquel momento, vasallo del rey Juan II.

Su hijo, Lope de León, no aparece en los libros de continos, pero sí en el registro del sello y los libros de Cédulas como contino al menos desde I499. En esta función tuvo un papel principalmente de tesorero, recibiendo continuamente comisiones entre los años I499 y I50I para recibir pagos o realizarlos en nombre de la Corona. En el año de I50o se alude a él alternativamente como «contino y pagador de los descargos del Príncipe Don Juan $»^{24}$ o «pagador/tesorero de los descargos de los reyes ${ }^{25}$. En realidad hay motivos para pensar que antes de aparecer en el registro del sello y los libros de cédulas como tesorero de los reyes ya actuaba como tal, puesto que aparece en septiembre de I498 en la reunión del ayuntamiento de Valladolid para recibir de manos de Alfonso de Verdesoto cierta cantidad de parte de la Hermandad General del reino ${ }^{26}$. Igualmente podríamos suponer que su actividad se extiende más allá de la última comisión conocida, en octubre de I5OI. Probablemente seguiría actuando como contino hasta heredar en enero de 1503 el cargo de canciller del sello de Valladolid y notario mayor del reino por fallecimiento de su hermano Francisco ${ }^{27}$. Parece evidente que no ejerció a la vez como contino y canciller, lo que podría ser resultado de que ambos oficios se considerasen incompatibles. En septiembre de I5I9 Lope arguyó que, debido a la necesidad de ocuparse de su hacienda y persona, no podría ejercer el oficio de canciller del sello del concejo y por ello lo renunciaba en Gómez de Ávila ${ }^{28}$.

El ejemplo de Lope de León es ilustrativo de dos tendencias que se pueden intuir a través del análisis de los casos vallisoletanos. Parece darse entre los continos dedicados a la gestión, por un lado, una situación más periférica dentro de las oligarquías locales y, por otro lado, una mayor correlación entre servicio y remuneración que entre los continos que prestaban un servicio militar. Como hijo segundogénito, Lope no estaba destinado inicialmente a heredar el cargo de canciller, lo que probablemente le impulsaría a buscar el servicio de los reyes a través del cargo de contino. Lope de León ejerció de forma especialmente activa como contino de los reyes entre, al menos, finales de 1498 y finales de I5OI, pero una vez ocupado el cargo de canciller, dejó de prestar servicio directo a la Corona ${ }^{29}$.

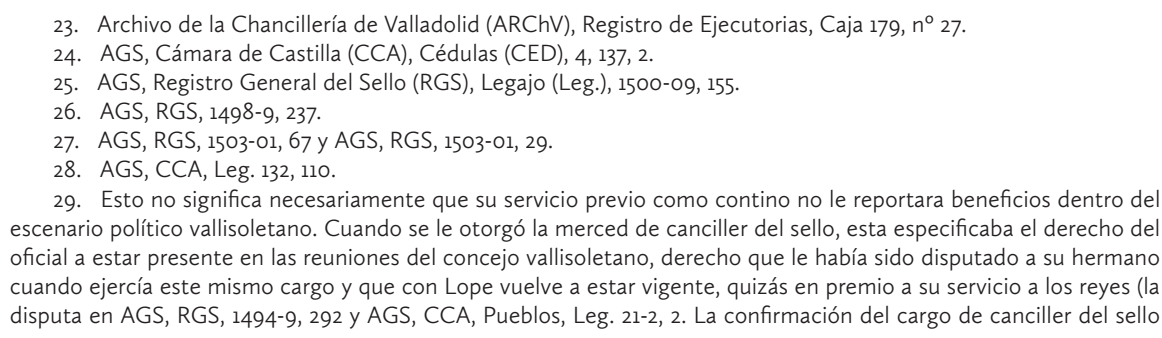

9. Esto no significa necesariamente que su servicio previo como contino no le reportara beneficios dentro de escenario político vallisoletano. Cuando se le otorgó la merced de canciller del sello, esta especificaba el derecho del oficial a estar presente en las reuniones del concejo vallisoletano, derecho que le había sido disputado a su hermano cuando ejercía este mismo cargo y que con Lope vuelve a estar vigente, quizás en premio a su servicio a los reyes (la disputa en AGS, RGS, 1494-9, 292 y AGS, CCA, Pueblos, Leg. 21-2, 2. La confirmación del cargo de canciller del sello 
A diferencia de Lope de León, muchos de los continos de Valladolid, lo fueron prestando un servicio eminentemente militar. Un ejemplo señalado es el del regidor Cristóbal de Santisteban. La familia Santisteban aparece en el regimiento de Valladolid al menos desde I475 cuando Alonso de Valladolid es elegido procurador de Cortes por el linaje de Tovar. Sus descendientes tuvieron una influencia considerable en el concejo vallisoletano y su nieto, Cristóbal de Santisteban, llegó a ser uno de los dos principales caballeros de las casas de Fernán Sánchez y los Mudarros $^{30}$. Alonso de Valladolid renunció su cargo de regidor en su hijo, Francisco de Santisteban, hijo asimismo de Isabel Álvarez de Orozco, al menos desde I478 $8^{31}$, mucho antes de morir. Francisco lo renunció a su vez en su hijo Cristóbal de Santisteban en algún momento entre febrero de 1505 y diciembre del mismo año ${ }^{32}$.

En I50 en una misiva de la reina a Francisco de Santisteban acerca de la concesión de una encomienda a Cristóbal, Isabel I prometía al padre que «seyendo el comendador vuestro hijo buen comendador e bien casado, quando el tiempo lo dispusiere avré memoria dél por lo quél e doña Ysabel su muger me han servido"33. En la misma carta se añadían unas palabras que sugieren algún tipo de desavenencia entre Francisco y su hijo, puesto que decía «e ruego vos que para servicio mío, los ayays encomendados e os ayays muy bien con ellos [con Cristóbal y su esposa] en lo qual me haréis mucho plaser e servicio». Estos roces paternofiliales parecen haber estado causados, entre otras cosas, por la afición de Cristóbal por el juego, como se puede deducir por el testamento de su padre ${ }^{34}$. Lo que interesa aquí, es notar el papel benefactor y casi maternal que la reina adopta en relación

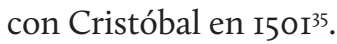

Cristóbal había sido recibido por la reina como contino ya en agosto de 1494 con una quitación de 30.000 maravedís. Sin embargo, en I495 era llamado a integrarse en la capitanía de los continos hombres de armas, donde serviría hasta I499, fecha en la que por cédula de la reina se ordenaba que se le volviera a librar su quitación como contino ${ }^{36}$. Pese a que inicialmente estaba sujeto a las pertinentes comprobaciones

a Lope de León incluido el mencionado derecho en AGS, CCA, Personas, Leg. 132, 110). Acerca de esta cuestión y en general de esta familia véase MARTín Romera, Ma Ángeles: Las redes sociales ..., pp. 317-321.

30. Los linajes vallisoletanos eran dos, el de Tovar y el de Reoyo, y a su vez se componían cada uno de cinco casas. Acerca de los linajes véanse: Rucquol, Adeline: Op.cit., p. 133 y ss., así como Martín Romera, Ma Ángeles: Redes de poder..., pp. 221-286.

31. ARChV, Pergaminos. $81, n^{\circ} 8$.

32. Archivo Municipal de Valladolid (AMV), Libro de Actas 2, fols. 197 y 203. Estos meses no aparecen en los libros de actas del concejo por lo que no se puede precisar la fecha, pero el 10 de febrero de 1505 Francisco aún era regidor y el 2 de enero de 1506 ya lo era su hijo.

33. AGS, CCA, CED, $5,287,3$.

34. AGS, CCA, Leg. 133, 68. Francisco testó en junio de 1518. En el testamento mejoró en un tercio a Cristóbal de Santisteban pero con varias condiciones. Entre ellas, que no jugara en su vida más de cinco o seis reales a las tablas y que si lo incumpliera que perdiera la mejoría. Seguramente Cristóbal era aficionado al juego y su padre temía que pudiera dilapidar la herencia.

35. Esta actitud probablemente se veía beneficiada por una relación adicional con la mujer de Cristóbal, Isabel de Ribadeneira, que con probabilidad era una de las damas de la corte. Una María de Ribadeneira aparece como ama de la princesa Isabel en 1494: AGS, RGS, 149407, 15 y AGS, RGS, 149406, 93.

36. En su asiento se señalaba que tenía cédula para que le librasen esos 30.000 maravedís «aunque no sirva por 
para recibir su quitación, en los años I5OI, I508, I5I2 y I5I3 se ordena que se le pague sin pedirle información de su servicio ${ }^{37}$. Finalmente en I5I4 el rey ordena que se le libre la quitación no solo de ese año, sino también de los dos próximos (I5I5 y I5I6) «20.00o cada año que el rey le hace merced en enmienda de los muchos y buenos y leales servicios que nos ha hecho e de los 30.000 que tiene de ración y quitación por contino de nuestra casa cada año» y, cumplidos dichos años, se le debían pagar en adelante los 20.000 maravedís de tres en tres años para en toda su vida, testándole de los libros de continos desde la fecha de dicha cédula. De esta forma se le conmutaban los 30.000 que había tenido hasta entonces como contino, cuyo último pago anotado en los libros se produce, efectivamente, en $\mathrm{I} 5 \mathrm{I} 3$, por una suerte de asignación de por vida que ya no estaba sujeta a comprobación, como en teoría lo estaban los servicios por contino.

Este ejemplo resulta muy ilustrativo de una tendencia brevemente señalada en la primera parte de este trabajo: la consolidación de una suerte de derechos adquiridos por parte de ciertos continos sobre su quitación, sin que a cambio presten el servicio al que teóricamente estaban obligados.

Una carta de I52I en que se concedía a una serie de continos de Valladolid servir desde su ciudad sin acudir a la guerra, muestra esta misma tendencia a consolidar el derecho de los continos militares a sus quitaciones anuales sin por ello requerir un servicio continuado ${ }^{38}$. Si bien el elemento común a todos ellos era el servicio de armas, aparece a menudo una correlación entre el perfil militar de los continos y su pertenencia a la oligarquía vallisoletana. En el caso de este documento de I52I, la mayoría de los mencionados eran regidores. Esta identificación entre servicio militar y regimiento resulta por otra parte natural en una villa en la que el perfil predominante de la oligarquía era el de caballería urbana con aspiraciones nobiliarias ${ }^{39}$.

En el caso de Cristóbal de Santisteban, no hay duda de que, más allá del servicio militar, otros factores propiciarían la conversión del cargo de contino en una suerte de merced: su oficio como regidor, la preminencia de su familia y del propio Cristóbal dentro de la oligarquía vallisoletana, además de su especial relación con la casa real, serían circunstancias determinantes. Es por ello que es preciso considerar en cada caso el lugar de los continos dentro de las oligarquías locales.

\footnotetext{
hombre de armas porque ha de servir y residir en la corte como los otros continos». AGS, EMR, CONTINOS, Leg. 8.

37. AGS, EMR, CONTINOS, Leg. 8.

38. En el expediente de Francisco de León en AGS, EMR, CONTINOS, Leg. 5-1.

39. Asenjo GonzÁlez, María: «Aristocratic ambitions in oligarchic urban society. Social and political consequences in fifteenth-century castilian towns», en AsEnjo GonzÁLEZ, María (ed.): Urban Elites and Aristocratic Behaviour in the Spanish Kingdoms at the End of the Middle Ages. Turnhout, Brepols, 2013, pp.49-60. MARTín Romera, Ma Ángeles: Redes de poder...pp. 47-51.
} 


\section{LA DIFERENTE INTEGRACIÓN DE LOS CONTINOS EN LA OLIGARQUÍA}

Más allá del papel que el oficio jugó en la política regia, es preciso comprender el significado del mismo para las élites urbanas castellanas. ¿Qué implicaciones tenía este servicio a la Corona en el ámbito local? ¿Cómo se conjugaba el ejercicio del cargo de contino o la designación como tal con los intereses personales y familiares de los habitantes del reino? ¿Qué significaba para las posibilidades de ascenso o consolidación social de la población castellana?

Para ello se ha seleccionado uno de los casos más relevantes de la Corona de Castilla, el de la villa de Valladolid. Esta villa cuenta con diversos estudios de conjunto $^{40}$, pero es en especial el trabajo de María Ángeles Martín Romera sobre la oligarquía de Valladolid y sus redes sociales el que ha proveído la información necesaria para complementar las fuentes centrales de la Corona ${ }^{4 \mathrm{I}}$.

En este estudio sobre la oligarquía de Valladolid se defendía el papel de las relaciones sociales como la principal base del poder de la oligarquía y, en general, del sistema de poder bajomedieval. Esta perspectiva se veía apoyada por la metodología del Análisis de Redes Sociales, una de las aplicaciones de humanidades digitales que más repercusión ha tenido en los estudios de historia económica y social en los últimos años ${ }^{42}$.

La red de la oligarquía de Valladolid y sus contactos entre 1450 y 1520 reconstruida en esta obra incorporaba a I.037 individuos ligados por 2.522 vínculos. En ella se puede observar a aquellas personas que fueron continos y analizar cuál fue su papel en el conjunto de la oligarquía. Uno de los mejores métodos es recurrir al parámetro de centralidad de cercanía, que sugiere en qué medida un actor tenía un lugar central y, por lo tanto, privilegiado, dentro del conjunto de relaciones que unía a esta red. La media de centralidad de cercanía de los continos identificados dentro de la red de la oligarquía vallisoletana asciende a $0,287^{43}$. Dicha cifra adquiere sentido al compararla con la centralidad de otros colectivos o de individuos concretos, por ejemplo, los regidores de Valladolid. La centralidad de los continos es ligeramente superior a la media de centralidad de todos los regidores, que es de 0,274. A pesar

40. Los más relevantes Rucquol, Adeline: op.cit. y BenNASSAR, Bartolomé: op.cit.

41. Martín Romera, Ma Ángeles: Redes de poder..., op.cit. y Las redes sociales ..., op.cit.

42. Por falta de espacio, ha de remitirse a los manuales básicos de Análisis de Redes Sociales y, sobre todo, al mencionado trabajo sobre la oligarquía vallisoletana para la comprensión tanto de esta metodología como de la aplicación concreta que se hizo, en el caso de Valladolid y sobre la cual se sustentan los datos aquí proporcionados. Útiles introducciones al Análisis de Redes Sociales en castellano son MolıNA, José Luis: El análisis de redes sociales. Una introducción. Barcelona, Edicions Bellaterra, 2001; y ReQuenA SANTOS, Félix: Análisis de redes sociales. Orígenes, teorías y aplicaciones. Madrid, Centro de Investigaciones Sociológicas, Siglo XXI, 2003, así como el volumen colectivo CARVAJAL DE LA VEGA, David et alii. (eds.): Redes sociales y económicas en el mundo bajomedieval, Valladolid, Castilla Ediciones D.L., 2011. Señal del interés de los historiadores por esta técnica es el reciente monográfico VV.AA: Las redes de poder en el mundo contemporáneo, Revista Ayer, 105 (2017-1).

43. Es importante señalar que de un total de 46 continos identificados como vallisoletanos, solo 33 de ellos aparecen en la red de la oligarquía vallisoletana reconstruida en MARTIN ROMERA, Ma Ángeles: Redes de poder... 
de ciertas consideraciones respecto a factores que pueden condicionar estas cifras, es indudable que en general el nivel de integración de los continos dentro de la oligarquía vallisoletana era notable ${ }^{44}$. Este resultado es consistente con las afirmaciones hechas por otros autores, como Ruiz Povedano que aseguró que los continos ocupaban una posición predominante en la ciudad de Málaga como parte de la élite local ${ }^{45}$, o los estudios de Montero Tejada acerca de la selección de continos como corregidores ${ }^{46}$. Sin embargo, más allá de esta correlación entre ser continos y formar parte de las élites urbanas, se ha avanzado poco en el análisis de cómo este cargo interactuaba con los intereses de estos individuos tanto a nivel local como en el reino.

El caso vallisoletano muestra que a principios del siglo XVI, es decir, en un lapso de tiempo muy breve desde el inicio del desarrollo del oficio de contino, éste se concebía ya como uno más de los objetivos a los que aspirar, dentro de un listado de elementos que se identificaban con la identidad de la oligarquía y con la cercanía a la Corona. A su vez, dentro de este listado abstracto de méritos a coleccionar por parte de las élites, el oficio de contino era más accesible que muchos de los otros, dado que en teoría se basaba en el servicio regio y no en la hereditariedad, la riqueza o los contactos. En la práctica tanto la hereditariedad, como los contactos ${ }^{47}$ o la riqueza (en especial en la medida en que esta posibilitaba la prestación del servicio militar) fueron factores importantes a la hora de alcanzar la consideración de contino, pero en cualquier caso nunca fueron requisitos sine qua non.

A pesar de este interés ampliamente difundido entre las élites por entrar a formar parte de las nóminas de continos, el uso que los distintos individuos hicieron del cargo o el significado que éste tuvo dentro de sus itinerarios personales y familiares difirió en función de distintos aspectos que pueden ponderarse mejor a través del análisis de una serie de ejemplos. En concreto se exponen aquí los itinerarios de dos familias de continos dentro del regimiento y de un individuo ajeno al regimiento que fue contino y a su vez un ejemplo paradigmático de los aspirantes a ascender dentro del escenario sociopolítico vallisoletano de este periodo.

44. La media comparativamente alta de los continos está influida por ciertos factores que alteran el resultado. Por un lado, algunos de los continos que probablemente harían descender la media no han sido identificados en la red por lo que no pueden ser tenidos en cuenta. Por otro, la red incluye individuos entre 1450 y 1520 , pero el periodo mejor documentado coincide con los registros de los libros de continos. Es decir, que mientras en la red hay regidores con un grado de centralidad muy bajo por haber pertenecido al regimiento muy brevemente o en periodos escasamente documentados, los continos identificados pertenecen al reinado de los Reyes Católicos o a reinados posteriores en los que es más fácil reconstruir las relaciones de los individuos.

45. Ruiz Povedano, José María: Poder y sociedad en Málaga: la formación de la oligarquía ciudadana a fines del siglo XV, Málaga, Diputación Provincial de Málaga, 1989.

46. Montero TejadA, Rosa $M^{a}$ : «Monarquía y gobierno concejil: ...», pp. 577-59o.

47. El obispo de Córdoba, primo del regidor de Valladolid Juan de Figueroa, escribió intercediendo por él para que recibiese compensación por haber servido al rey durante las Comunidades y en concreto solicitó que el rey lo recibiese como contino, añadiendo que en esto también el obispo recibiría merced: AGS, CCA, Leg. 144, 33. 
Las dos familias de continos en el regimiento de Valladolid consideradas aquí son los Alcocer y los Franco ${ }^{48}$. Los primeros regidores de estas familias fueron el Doctor Juan Díaz de Alcocer y García Franco, ambos pertenecían a familias con tradición de servicio regio y partieron de condiciones muy similares ${ }^{49}$. Sin embargo, la deriva de ambas familias tanto en relación con el servicio regio como en su integración dentro de la oligarquía de Valladolid, siguió cauces muy diferentes. La familia Franco abrazó en la segunda generación los ideales aristocráticos y guerreros ligándose a familias importantes como el conde de Benavente, mientras que los Alcocer se mantuvieron en oficios de servicio regio de corte no militar. Como consecuencia, la admisión de la segunda generación de ambas familias como continos se produjo en momentos diferentes de la política regia y con perfiles de servicio muy diversos.

Tras la muerte de Enrique IV, en I477 los Reyes Católicos decidieron poner en orden las deudas del reino y para ello recurrieron a Alfonso de Quintanilla, el doctor Juan Díaz de Alcocer, García Franco y a Alfonso de Valladolid ${ }^{50}$. Tres de estos cuatro contadores fueron regidores de Valladolid. A diferencia de Alonso de Valladolid que era originario de la villa de Valladolid y cuya pertenencia a la élite local así como su relación con el Almirante de Castilla precedieron su acceso al regimiento, en el caso de los Alcocer y los Franco el acceso al regimiento llegó gracias a una merced regia que compensaba sus servicios a la Corona.

García Franco era hijo de Diego González de Toledo, conocido como el Doctor Franco, quien fue contador mayor de cuentas, oidor y refrendario de Juan Il, así como miembro de su Consejo. García Franco accedió al cargo de contador mayor de cuentas al servicio de los Reyes Católicos y fue miembro de su Consejo, pero de forma paralela desarrolló un perfil aristocrático y guerrero al servicio del conde de Benavente, Don Rodrigo Alfonso Pimentel. Ya en 1475 había luchado junto al conde en Baltanás, donde fueron derrotados por los portugueses.

Por su parte, en 1475 el doctor Juan Díaz de Alcocer ya acumulaba los cargos de oidor de la Real Audiencia, miembro del Consejo Real, contador mayor de cuentas y recibía la merced de las escribanías de las rentas de las merindades de Castrojeriz y Cerrato ${ }^{5}$. En I477 el rey, confiando en su prudencia y fidelidad le nombró secretario, escribano de cámara y notario público de su corte para toda su vida ${ }^{52}$.

\footnotetext{
48. Para una comparativa de la integración de estas familias en la oligarquía de Valladolid véase MARTín RomerA, $M^{a}$ Ángeles: Redes de poder..., pp. 108-113.

49. Sobre la familia del Doctor Juan Díaz de Alcocer véase RÁbade Obradó, Ma Pilar: «El doctor Juan Díaz de Alcocer: apuntes biográficos de un servidor de los Reyes Católicos», Espacio, Tiempo y Forma, Serie III, Ha Medieval, 3 (1990), pp. 259-287 y sobre la familia Franco, MARTín RomerA, Ma Ángeles: Las redes sociales..., pp. 294-306.

50. AGS, RGS, 1477-12, 540; AGS, RGS, 1478-12, 192.

51. AGS, RGS, 1475-06, 493.

52. AGS, RGS, 1477-01, 6.
} 
Como miembros del Consejo real y contadores mayores de cuentas García Franco y el doctor Juan Díaz de Alcocer coincidirían en comisiones conjuntas al servicio de los reyes en I477 y I47853. García Franco fue regidor de Valladolid al menos desde 1465 y en las Cortes de Toledo de 1480 fue procurador por la citada villa. El doctor Díaz de Alcocer ingresó más tardíamente en el concejo de Valladolid, también gracias al servicio a los reyes, en $1494^{54}$.

Con trayectorias profesionales similares y siendo ambos regidores de Valladolid, el Análisis de Redes Sociales reveló que su integración en la oligarquía vallisoletana fue diferente y consecuencia de estrategias dispares, mientras que García Franco mostró interés por entrar en contacto no sólo con la nobleza sino con otros miembros de la oligarquía, estableciendo lazos de parentesco a través de los matrimonios de sus hijos con otras familias de regidores, los contactos del Doctor Díaz de Alcocer con la oligarquía de la villa eran mucho más limitados y, en gran parte, dependían de su relación con la monarquía. Estas diferentes estrategias hicieron que el nivel de integración de los Alcocer dentro de Valladolid fuera mucho menor que el de la familia Franco, que adquirió un mayor poder e influencia ${ }^{55}$.

Por otra parte, mientras que García Franco y el doctor Díaz de Alcocer fueron servidores regios de forma contemporánea, el acceso de sus vástagos al oficio de contino estuvo separado por un periodo de tiempo considerable y, por lo tanto, se produjo en circunstancias sociopolíticas muy diferentes. En el caso de García Franco tres de sus hijos fueron asentados como continos reales: en 1485 Pedro y Francisco de Cartagena ${ }^{56}$ y en 1489 Alonso de Sarabia. Pedro de Cartagena moriría en combate poco después, en I486, año en el que también fallecería García. De Francisco de Cartagena solo tenemos constancia de su asentamiento pero no de su servicio (de hecho tampoco consta que se le hiciera ningún libramiento), sin embargo, una noticia de 1503 confirma el carácter militar del servicio de Pedro de Cartagena ${ }^{57}$. Todos los hijos de García Franco fueron asentados con una ración y quitación anual de 40.000 maravedís, cantidad considerable pero acorde con su posición social, salvo el primogénito. Antonio Franco no fue recibido como contino real, probablemente por ser el heredero del mayorazgo y su sucesor en el regimiento de Valladolid y en los cargos de contador mayor de cuentas de los reyes y miembro de su consejo, cargos que ya se le atribuyen en I486, en la carta de compromiso que en junio de ese año habían firmado los

\footnotetext{
53. AGS, RGS, 1477-12, 540 y RGS, 1478-12, 192.

54. AGS, RGS, 1494-12, 30 .

55. Martín Romera, Ma Ángeles: Redes de poder..., pp. 108-113.

56. Si bien en la relación de hijos de García Franco que en su día proporcionaba Martín Romera (2012), no figura Francisco de Cartagena, éste es identificado como su hijo en el albalá de nombramiento de contino por el que la reina le recibe para que le sirva continuamente (AGS, EMR, CONTINOS, Leg. 2)

57. AGS, CCA, CED, 6, 80, 1. En este año se instaba a Martín de Salinas, tesorero de los descargos de la reina, que pagara a los herederos de Pedro de Cartagena 40.000 maravedís de su quitación «por contino de mi casa del año pasado de 1486 que sirvió y le mataron en el combate del arrabal de Loja».
} 
hermanos para evitar disputas y conflictos sobre la herencia de García Franco ${ }^{58}$. En cuanto al tercer hijo contino de García Franco, Alonso de Sarabia, se integró en la capitanía de los continos en $1495^{59}$ y continuó sirviendo militarmente en la guerra del Rosellón en I503. Sin embargo, la ductilidad del oficio de contino

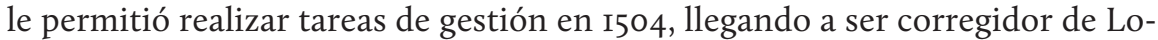
groño en 1508 , y más tarde integrarse en la corte como maestresala ${ }^{60}$. Su larga carrera como contino se vería finalmente truncada por su participación en las Comunidades que le llevó no solo a ser despedido, sino al extremo de recibir la pena máxima ${ }^{61}$.

En el caso de la familia Alcocer, el Doctor Díaz de Alcocer tuvo dos hijos varones, Cristóbal, probablemente el primogénito, y García de Alcocer, quien en principio parecía estar destinado a la vida eclesiástica ${ }^{62}$. Sin embargo, y por motivos que desconocemos, en abril de i499 García recibía de los reyes, por renunciación de su hermano el bachiller Cristóbal de Alcocer, una merced de por vida de la carnicería franca de la ciudad de Valladolid y otra por la que sustituía a Cristóbal en el regimiento de la citada villa, coincidiendo en el concejo con su padre que aún era regidor ${ }^{63}$. En esta fecha ninguno de los dos hijos había sido asentado como contino real. De Cristóbal no se vuelve a tener noticias y García, siendo ya regidor, sería recibido por los reyes como contino de su casa en agosto de 1502 con una quitación anual de 40.000 mrs. El 28 de agosto de 1506 volvía a ser asentado como contino real, pero esta vez por el rey Felipe. De su servicio como contino poco sabemos y aunque en los primeros años se le libró su quitación de forma ininterrumpida, no parece que se le encomendara ningún servicio concreto ${ }^{64}$.

Estos dos itinerarios de dos familias con una situación muy similar en sus inicios en el servicio a la Corona muestran dos modelos en los que el papel del cargo de contino tuvo un significado muy diferente. Por un lado se comprueba que, coincidiendo con una coyuntura política favorable al servicio militar, ya que

58. AGS, EMR, Mercedes y Privilegios, Leg. 61, fol. 28.

59. AGS, CCA, CED, 2, 2-2, 7, 1 .

6o. AGS, RGS, 1504-06, 415, donde se encomienda a Alonso de Sarabia que se junte con la persona que designe el rey de Portugal para entender en los debates sobre términos que mantienen las villas Aroche y Encinasola con los lugares portugueses de Moura y Nodal (10/06/1504). En 1518 se ordenaba que se le pagara su quitación de contino del año 1517 «no enbargante que sea maestresala del señor infante».

61. Despedido desde enero de 1521, su asiento fue entregado a Pedro de Beamonte (AGS, EMR, CONTINOS, Leg. 8). Acerca de Alonso de Sarabia, además de las obras de Martín Romera, Ma Ángeles: Redes de poder..., y Majo TOMÉ, Beatriz: op.cit., véase SuÁrez VARelA, Antonio: «La Comunidad de Valladolid y la cuestión conversa: el caso del procurador Alonso de Saravia» en SzÁszdi León-Borja, István y GaLende Ruiz, María Jesús (eds.): Carlos V, conversosy comuneros: 'liber amicorum' Joseph Pérez. Valladolid, Centro de Estudios Camino de Santiago Sahagún, 2015, pp. 259-351.

62. En junio de 1492 se presentaba una canonjía en la catedral de Granada en favor de García de Alcocer, estudiante de cánones en el Estudio de Salamanca (AGS, RGS, 1492-06, 66).

63. AGS, RGS, 1499-04, 3 y AGS, RGS, 1499-04, 26.

64. Se le libró su quitación desde 1502 a 1509 ininterrumpidamente. En 1507 obtuvo licencia del rey para «se quedar acá» y no ir a Andalucía con él. En 1508 estuvo en Burgos hasta que el rey partió de allí. En 1513 se le libraron 10 meses que residió en la corte, en 1516 dos meses de servicio y en 1517 cobró por cuatro meses de residencia. AGS, EMR, CONTINOS, Leg.1. 
los reyes necesitaban sostener sus distintas campañas bélicas, las familias con un perfil guerrero tendieron a tener una mayor presencia entre los continos colocando a múltiples de sus miembros al servicio de los reyes. Dado que el perfil militar es el predominante en el concejo vallisoletano, tanto los ideales aristocráticos como el servicio conjunto en las campañas bélicas contribuirían a estrechar lazos entre los miembros de estas familias, compañeros en batallas y en estilo de vida.

En I495, durante los preparativos para la ocupación del reino de Navarra, los reyes escribieron a una serie de continos, ordenándoles incorporarse a la capitanía de Alfonso de Fonseca, señor de las villas de Coca y Alaejos y capitán de los continos. Entre los convocados a esta capitanía se encontraban cinco regidores vallisoletanos: Alonso Niño de Castro, Pedro Niño, Juan de la Cuadra, Jorge de León y Juan de Morales, así como Cristóbal de Santisteban ${ }^{65}$.

Asimismo, el perfil aristocrático-militar conllevaba una potencial hereditariedad de las prebendas y bienes y una mejor transmisión del estatus, lo que parece haberse extendido pronto a aspectos como la inclusión en la nómina de continos. En el caso de los Franco tres hijos fueron integrados como continos por su capacidad para servir militarmente. En el de los Alcocer, solo un hijo se incluye como contino y esto ocurre cuando ya es regidor y sin que se compruebe ningún servicio específico. Esto sugiere que su nombramiento responde a la equiparación entre regidor y servidor regio así como a la intención de acumular una serie de prebendas que se esperaban de una persona de su rango y que, desde inicios del siglo XVI, incluía la consideración de contino y las quitaciones correspondientes.

Por otra parte, el oficio de contino tiene un valor distinto entre los segundones y los primogénitos. Mientras que para estos últimos el cargo se entiende como un vínculo más con la Corona que completa su perfil como oligarca, entre los segundogénitos se trata de una vía fundamental para intentar asociarse a la Corona, toda vez que se ven parcialmente excluidos de los principales cargos locales (entre los que el regimiento sería el más destacado) así como de una serie de bienes y prebendas tangibles o intangibles asociados a la primogenitura: desde el mayorazgo hasta oficios diversos, como las encomiendas o en el ya mencionado caso de la familia León, el cargo de canciller del sello.

La identificación entre oligarquía y contino o, de forma más abstracta, servicio a la Corona, provocaría que otros individuos que aspiraban a medrar viesen el cargo como una de las estrategias más accesibles. Un ejemplo claro de persona que intenta escalar dentro del ecosistema vallisoletano es Francisco Tamayo, exponente de lo que se ha llamado élite del común ${ }^{66}$ y uno de los casos más claros de ascenso durante los turbulentos años que precedieron a la revuelta de las Comunidades.

65. AGS, CCA, CED, 2, 2-2, 7, 1, de fecha 23/06/1495. Cristóbal de Santisteban sería regidor a partir de 1505.

66. VAL VALDIVIESO, $M^{a}$ Isabel del: «Ascenso social y lucha por el poder en las ciudades castellanas del siglo XV.» En la España Medieval, 17 (1994), pp. 157-184. 
Una de las características que hacen de Tamayo un caso especialmente interesante es que desde que la documentación registra su aparición en el escenario político vallisoletano, se observa que este miembro del común recurrió a un amplio abanico de estrategias con la intención de promocionarse. Estas estrategias, en las que obtuvo un éxito dispar, incluyeron ser contino, intentar acceder a los linajes de caballeros urbanos, ponerse al servicio de varios regidores y acceder al cargo de procurador del común, acciones todas ellas que culminaron con Tamayo siendo uno de los capitanes de la Junta Comunera ${ }^{67}$.

Antes de I5I2 solo hay una mención en el Registro General del Sello que parece corresponderse con el mismo Francisco de Tamayo aquí referido. Se trata de un mandamiento de los reyes de 1498 en el que se ordena a Juan de la Torre que se realicen ciertos pagos a petición de Francisco de Tamayo que actúa en nombre de las gentes de la capitanía del comendador Ribera, regidor de Valladolid. Según dicho documento, Tamayo habría sido ya entonces gestor del regidor en su capitanía ${ }^{68}$. Desde 1512 Tamayo figuraba ya en la nómina de continos, pero es a partir de I5I7 cuando definitivamente destaca dentro del escenario político vallisoletano ${ }^{69}$.

Tamayo intentó ingresar en los linajes vallisoletanos en I5I7. Los linajes de caballeros urbanos, como en otras ciudades castellanas, controlaban el acceso a una serie de oficios concejiles, aunque a finales del siglo XV estaban ya fuertemente mediatizados por los regidores ${ }^{70}$. Francisco de Tamayo fue presentado como candidato en las casas de Fernán Sánchez y los Mudarros (pertenecientes al linaje de Tovar) por el regidor Rodrigo de Verdesoto en enero de I5I7 (lo que denota un cierto vínculo clientelar también con este regidor). Su presentación coincidió con la primera oposición frontal de las casas a aceptar a una serie de nuevos miembros. Esta reacción fue sin duda una consecuencia de los conflictos entre la oligarquía y la comunidad de Valladolid que desde I5I6 habían cobrado especial intensidad y que se saldarían con la victoria de la comunidad en junio de I5I7, cuando el cardenal Cisneros, como regente, confirmó la creación del oficio de procurador del común en la villa. La candidatura de Francisco de Tamayo, y la de otros

67. Acerca del papel de Tamayo dentro de la Junta Comunera véase MAjo TOMÉ, Beatriz: op.cit., para todo lo demás véase Martín Romera, Ma Ángeles: Redes de poder..., pp. 245-247, 314-315, 340-34.

68. AGS, RGS, 149807, 81.

69. AGS, EMR, CONTINOS, Leg. 8.

70. La cuestión de los bandos y linajes ha sido especialmente prolífica en la historiografía española, entre otros estudios pueden verse: LADERO QUESADA, Miguel Ángel: «Linajes, bandos y parcialidades en la vida política de las ciudades castellanas (Siglos XIV y XV)» en Bandos y querellas dinásticas en España al final de la Edad media/ Actas del Coloquio celebrado en la Biblioteca Española de París los días 15 y 16 de mayo de 1987. Madrid: Ministerio de Asuntos Exteriores, Dirección General de Relaciones Culturales, 1991, pp. 105-134.; DIAGO Hernando, Máximo: «El papel de los linajes en las estructuras de gobierno urbano en Castilla y en el Imperio alemán durante los siglos bajomedievales», En la España Medieval, 20 (1997), pp. 143-178.; Monsalvo AnTón, José María: «Parentesco y sistema concejil. Observaciones sobre la funcionalidad política de los linajes urbanos en Castilla y León (siglos XIII-XV)». Hispania, 53-185 (1993), pp. 937969.; ACHÓN INSAUSTI, José Ángel: «A voz de Concejo»: linaje y corporación urbana en la constitución de la Provincia de Guipuzkoa: los Báñez y Mondragón, siglos XIII-XVI. San Sebastián, Diputación Foral de Gipuzkoa, 1995; DAcostA, Arsenio F.: Los linajes de Bizkaia en la Baja Edad Media: poder, parentesco y conflicto. Bilbao, Universidad del País Vasco, 2003. 
individuos, fue rechazada muy posiblemente porque los linajes le identificaban como políticamente vinculado a la comunidad ${ }^{7 \mathrm{r}}$.

El fracaso en este frente sería un aliciente para una participación aún más activa en el seno de la comunidad que le llevó a ser nombrado uno de los primeros procuradores del común de la villa. Su actividad como procurador del común está extensamente documentada, especialmente en las actas concejiles, y muestra numerosas acciones como portavoz de la comunidad ${ }^{72}$, sin embargo, el i4 de marzo de I5I9 fue sustituido por Francisco de Torquemada, bajo la premisa de que Tamayo no servía el oficio ${ }^{73}$. Capitán y diputado de la junta comunera, aparece en el listado de continos a los que se les quitó su asignación en abril de I52I porque «an estado y estan en nuestro deserviçio con las comunidades que se an levantado en estos nuestros reynos contra nuestro serviçio» ${ }^{74}$. En ella Tamayo figuraba con 35.000 maravedís junto a otros exponentes tanto de la oligarquía como de los diputados comuneros, entre los que se encontraba el ya mencionado Alonso de Sarabia, hijo del regidor García Franco ${ }^{75}$. El cargo de contino se mostraba así como un objetivo común tanto de los regidores y sus familias, como de los individuos que procuraron ascender políticamente durante este periodo.

\section{DEFINIENDO EL OFICIO DE CONTINO}

Los tres ejes expuestos, aunque de distinta forma y a distintos niveles, repercutieron en las condiciones que definían el propio cargo de contino. Uno de los aspectos más significativos en relación con la definición de oficio son las dos tendencias aparentemente contradictorias que aparecen ya desde el reinado de los Reyes Católicos y que se han apuntado someramente en los previos apartados.

Por un lado, se identifican claros esfuerzos dirigidos al control efectivo de estos oficiales: en qué han servido, cuánto tiempo han servido y si han residido de hecho en la corte tal y como su cargo requiere. Por otro lado, ya con los Reyes Católicos, pero aún más claramente a raíz de la política conciliatoria que Carlos V adopta tras la derrota de las Comunidades, el cargo de contino va a adquirir rasgos propios de otros oficios, como la hereditariedad vía renuncia, su carácter de merced y, sobre todo, una interpretación mucho más laxa de la retribución por servicio ${ }^{76}$.

71. Todos estos hechos fueron analizados por Martín Romera, Ma Ángeles: Las redes sociales... y Redes de poder..., pp. 299-356. Además de Francisco de Tamayo, las personas no admitidas fueron Fernán López de Calatayud y Francisco López de Calatayud. Sobre estos, tras dar todos sus votos y pareceres «acordaron que no se devían de reçibir e que no les reçibían ni reçibieron».

72. Por ejemplo en AMV Libro de Actas 4, fols. 152r-152V.

73. AMV, Libro de Actas 4, fol. $526 \mathrm{r}$.

74. AGS, EMR, Nóminas, Leg. 2, fol. 51.

75. Ibídem.

76. Mientras que Martínez Millán, José y Ezquerra Revilla, Ignacio, Op.cit., pp. 349-353, proponían un eje cronológico con un cambio claro a partir del establecimiento de la corte en Madrid a mediados del siglo XVI, estos 
La primera tendencia se manifiesta abiertamente en los libros de continos, donde junto a las quitaciones se especifican los servicios concretos y el tiempo de servicio, como justificación directamente ligada al emolumento asociado al cargo. Los registros parecen encarnar a la perfección una idea de justicia distributiva con evidentes connotaciones cuantitativas. Esta equivalencia entre lo servido y el pago recibido comienza a acompañarse pronto de ciertas excepciones que irán socavando dicho modelo.

Desde fines de la década de los noventa, pero más claramente desde inicios del s. XVI, el registro en el libro de continos idealmente especificaba los meses servidos por cada año, el tipo de servicio y la paga correspondiente. Por ejemplo, al regidor de Valladolid Jorge de Herrera se le reconocen cuatro meses que residió en I5IO, diez en I5I3, tres en I5I8 y 5 en I52I. En 1526 se señala no que residió en la corte, sino que sirvió yendo a tomar los alardes a la gente de acostamiento ${ }^{77}$. Resulta significativo respecto a la relación directa entre servicio y quitación, cómo el servicio de contino parece ser incompatible con el desempeño de otros cargos y, cuando esto ocurre, no ha de pagársele su quitación. Siguiendo con el mismo ejemplo, mientras Jorge de Herrera ocupó el cargo de corregidor de Ávila, se consideró que no había de recibir su quitación como contino, y así al margen de I5I8 y I52I se anota «por cédula y mandamiento de contadores e fe del tiempo que tovo la vara de corregimiento de Ávila» y se le abonan tan solo los meses que residió en la corte $u$ otras partes en servicio de sus majestades previa y posteriormente a dicho corregimiento ${ }^{78}$.

Aún más explícito es el caso de Alonso de Sarabia, hijo del corregidor García Franco y posterior protagonista de las Comunidades. Siendo contino desde I489 con 40.000 maravedís de quitación, en I509 se ordena que se le pague «lo que monta aver de la dicha su quitación de contino del tiempo que no a seydo corregidor el año pasado de quinientos e ocho». De hecho, el bachiller Francisco de Espinosa, vecino de Logroño, dio fe del tiempo que Sarabia fue corregidor de Logroño ${ }^{79}$. También se señalaba que se le pagaran tanto 1506 como 1507 completos sin información de servicio, añadiendo que se ocupó «en cosas de mi servicio». Sin embargo, en I5Io el propio Alonso de Sarabia reclamó que se le pagara su quitación de contino de 1508 incluido el tiempo que había estado ausente de la corte, considerando que en el ejercicio del corregimiento de Logroño había estado al servicio del rey, argumento que el rey tomó por bien. En I5I7 se vuelve

\footnotetext{
datos sugieren que las tendencias entre un modelo de oficio estrictamente basado en el servicio y otro con un carácter más honorífico o como merced económica, existían ya de forma contemporánea en la primera mitad del siglo XVI, sin que una tendencia excluyese a la otra.

77. AGS, EMR, CONTINOS, Leg. 4 .

78. Acerca de la familia Herrera véase Martín Romera, Ma Ángeles: Las redes sociales ..., op.cit., pp. 307-309.

79. AGS, EMR, CONTINOS, Leg.8. Este corregimiento duró tan solo un año (de octubre de 1507 a octubre de 1508) lo que, a pesar de que así lo estipulaban las normas de corregidores constituía un caso excepcional y como tal lo analiza Diago HeRnANDo, Máximo: «El papel de los corregidores en los conflictos políticos en las ciudades castellanas a comienzos del siglo XVI», En la España medieval, 27 (2004), pp. 195-223 (p. 215).
} 
a producir una duplicidad de cargos, esta vez como contino y, al mismo tiempo, maestresala del señor infante $y$, aunque se entiende como un impedimento, se ordena que se le libre su quitación no embargante el segundo oficio.

Otro ejemplo de incompatibilidad por duplicidad de cargos se alega en I5I8 en virtud de que Pedro de Montemayor, hijo del regidor de Valladolid Alonso de Montemayor, en vida del rey Fernando tenía asiento y quitación de cazador y, al mismo tiempo, pretendía quitación como contino ${ }^{80}$. El rey ordenó que se investigara y si era así que en tiempos del rey Fernando tenía ambos asientos y cobraba por ellos, siguiera pagándosele de igual forma. Por este motivo, Lope de Ribera, oficial de quitaciones, tomó juramento a Juan de Estrada, contino, y a García de Montalbán, vecino de Medina del Campo, que testificaron que Pedro de Montemayor había sido cazador del rey Fernando y cobraba por ello ${ }^{8 \mathrm{r}}$. Como se observa, a pesar de la aparente incompatibilidad para ejercer dos cargos y cobrar por ellos al mismo tiempo, la realidad es que nos encontramos con muchas excepciones.

El recurso a la declaración de testigos era habitual para determinar las quitaciones. Por lo general otros continos juraban haber visto al contino en cuestión bien en la corte o bien en otro lugar donde habrían servido a los reyes. Por ejemplo, en el caso de Fernando de Illescas, hijo del licenciado Gonzalo González de Illescas del Consejo y recibido por contino en I503, en I508 se especifica que cumplió con siete meses de residencia y que no fue a Andalucía. Dos continos, Antonio de Ribera y Gonzalo de Morales, afirmaron haberlo visto en Burgos en I508 y otro contino, Antonio de Carranza, juró que sabía que estuvo en Valladolid los meses de octubre a diciembre de $1509^{82}$.

En algunos casos se alude incluso a que las probanzas aportadas por parte del contino han sido insuficientes. El contino Pedro de Ribera aporta probanzas para el año de I508 a través de dos testigos continos (Fernando de Illescas y García Sarmiento de Ribera) y de 1509 con tan solo un testigo (García Sarmiento de Ribera). Mientras que para 1508 se le libran 7 meses, para I509 se indica que dé más probanzas o, si no, se le libren sólo los cuatro meses que tiene de residencia de ese año ${ }^{83}$.

Sin embargo, en contraste con estas anotaciones que acotan el servicio realizado y recurren a testimonios que confirmen el mismo, aparecen otras en las que es el rey o la reina el que se erige en garante del servicio de sus continos abortando la prosecución de probanzas o informaciones respecto a dicho servicio. En estos casos, por lo general, los monarcas no detallan las tareas concretas en las que los

80. AGS, CCA, Leg. 123, 64. Resulta difícil discernir hasta qué punto el cese en su quitación se correspondía con dicha duplicidad o era consecuencia de la muerte de su principal benefactor, Fernando el Católico, de quien había sido criado y cazador. En mayo de 1517 reclamaba su quitación del año 1516 y suplicaba que, porque estaba en la corte en e servicio real y había servido en la guerra, se le librara como se le había librado hasta la muerte de Fernando el Católico.

81. AGS, EMR, CONTINOS, Leg. 6.

82. AGS, EMR, CONTINOS, Leg. 5-1.

83. AGS, EMR, CONTINOS, Leg. 7. 
continos han servido. En el caso de Diego de Ribera, hijo del alcaide de Burgos y pariente de los Ribera regidores de Valladolid ${ }^{84}$, en 1503 la reina manda que se le pague lo que ha de haber ese año y el venidero de 1504 sin pedirle información de servicio por cuanto „es ido a nos servir a la guerra al rey mi señor e a mi« y en 1505 se ordena que se le pague su quitación por trinchante de la reina lsabel de 1504 sin información de servicio pues ha estado en León y Cartagena «en cosas cumplideras al servicio del rey» ${ }^{85}$. De forma similar, en el ya mencionado caso de Alonso de Sarabia se ordena que se le pague todo el año de I504 porque durante parte del mismo simplemente «entendió en cosas complideras al servicio del rey» ${ }^{86}$.

Esta tendencia a conmutar las probanzas por la fe que aporta el rey, aunque a menudo se corresponde con un servicio real, abre la puerta a una concepción más laxa del oficio de contino como una suerte de retribución a una serie de personas especialmente ligadas al servicio de la Corona. En este caso, la relación entre continos y monarcas se vuelve más ambigua y recuerda a una relación de servicio personal, una suerte de acostamiento, en la que las obligaciones concretas aparejadas con el cargo no siempre se hacen explícitas o efectivas.

De hecho, en ocasiones, el pago se admite no en virtud de un servicio realizado, sino del que se espera recibir del contino. En el caso de Juan Niño de Castro, hijo del merino mayor y regidor de Valladolid Pedro Niño ${ }^{87}$, en $15 \mathrm{IO}$ se ordena que se le paguen los años de 1509 y I5Io sin pedirle información de servicio «por cuanto va a servir en esta guerra de allende con los otros que allá pasan» ${ }^{88}$.

A pesar de que esta tendencia se hace más evidente a raíz de las Comunidades, ya desde el reinado de los Reyes Católicos se estaba gestando esta transición. Protegido por la reina Isabel, Cristóbal de Santisteban es desde joven uno de los continos de su casa y desde pronto se suceden concesiones de quitaciones sin haber prestado un servicio concreto. No quiere decir esto que no sirviera en absoluto: como ya se ha señalado, en 1508 se dice que en 1507 sirvió en la guarda del infante don Fernando y en I5Io presenta testigos para probar que tiene nueve meses de residencia. Sin embargo, en muchos de estos años es pagado sin

84. Acerca de la familia Ribera véase Martín Romera, Ma Ángeles: Las redes sociales ..., pp. 334-342. Diego de Ribera era sobrino de Pedro de Ribera, primer regidor de Valladolid de esta familia. Asimismo fue primo del siguiente regidor de esta familia, el homónimo Diego de Ribera, comendador de la orden de Santiago, quien al menos desde 1507 era camarero de la reina y recibía además 30.000 maravedís por contino (AGS, EMR, Nóminas, Leg. 1, fol. 41; AGS, EMR, Nóminas, Leg. 1-2, fol. 313; AGS, EMR, Nóminas, Leg. 1-2, fol. 324).

85. AGS, EMR, CONTINOS, Leg. 7.

86. AGS, EMR, CONTINOS, Leg.8.

87. El propio Juan Niño de Castro sería nombrado regidor y merino mayor, tal y como recogen sus asientos de contino. Sin embargo, Juan apenas llegó a hacer un uso efectivo de dichos cargos, ya que se trató en realidad de un intento de su padre de castigar al primogénito, Alonso Niño de Castro, retirándole los oficios que previamente había renunciado en él. La disputa que se originó entre ambos herederos y Pedro Niño que tomó partido por Juan, no se resolvería hasta la muerte de Juan Niño, cuando Alonso quedó definitivamente como heredero del regimiento y la merindad (MARTín Romera, Ma Ángeles: Redes de poder..., pp. 154-156).

88. AGS, EMR, CONTINOS, Leg. 6. 
probar servicio alguno y la prueba más palpable de que el cargo de contino se convierte en su caso en una suerte de gracia económica y de lazo especial con la Corona es la decisión de Fernando de conmutar su quitación de contino de 30.000 maravedís anuales por una merced de 20.000 anuales exenta de servicio.

A partir de 1520 esta tendencia se ve favorecida por la necesidad de recompensar a las élites urbanas que habían luchado a favor del emperador en las Comunidades. Esto propiciará que las quitaciones como contino se otorguen en ocasiones a modo de compensación por haber sufrido pérdidas en servicio del rey. En julio de 1522 se ordena que se le pague por completo el año presente a Pedro Núñez de la Serna sin que aporte información de servicio y a pesar de no haber terminado el año: «por cuanto por ser servidor nuestro fue robado en tiempos de las alteraciones pasadas y ha recibido muchos daños e pérdidas» ${ }^{89}$.

Muy significativa es otra decisión del rey en I52I en la que ordenaba al regidor y contino Francisco de León que, mientras no se le mandara otra cosa, permaneciera en la villa de Valladolid, aunque apercibido para ir a la guerra de Navarra contra los franceses. Esta orden no solo afectaba a Francisco de León sino, como muestra una carta del Almirante Gobernador del reino, incumbía a una serie de continos regidores y escuderos de Valladolid que debían permanecer en la villa «sin que hayan de acudir a la guerra». Estos eran los regidores Cristóbal de Santisteban, el doctor Villarroel, Rodrigo de Verdesoto y Alonso de Montemayor, así como el propio Francisco de León y Fernando de Illescas, escuderos de acostamiento ${ }^{90}$. Tanto el año I52 I como I522 se librarían enteramente a Francisco de León, pues los señores gobernadores le daban por bien servido estando en Valladolid. Si bien se arguye que su servicio era requerido en la propia Valladolid, es innegable que como regidores y residentes de dicha villa, la posibilidad de servir en la misma en lugar de desplazarse al frente y al mismo tiempo recibir quitación debe interpretarse casi como una merced.

Sin duda, una de las manifestaciones más evidentes del desarrollo de una suerte de derechos adquiridos de los oficiales sobre el cargo de contino es su renunciación en otra persona, principalmente el primogénito. Dicha renuncia tenía un carácter análogo a las realizadas en los casos de los cargos de carácter vitalicio como los regimientos ${ }^{91}$. Juan de Luzón, contino desde I5II con quitación de 40.000 maravedís, renunció a su asiento en su sobrino Antonio de Luzón en 1528 y el rey lo recibió por tal. El hermano de Antonio, Francisco, ya había accedido al cargo de contino en I52 I por sustitución de su padre, el regidor de Madrid Antonio de Luzón ${ }^{92}$. Sin embargo, no es raro que ambos padre e hijo fue-

89. AGS, EMR, CONTINOS, Leg. 6.

90. La citada carta aparece en el expediente de Francisco de León en AGS, EMR, CONTINOS, Leg. 5-1.

91. Aunque no en todas las ciudades las regidurías eran vitalicias o hereditarias, es indudable que esta era la tendencia mayoritaria en Castilla y el modelo predominante en Valladolid.

92. AGS, EMR, CONTINOS, Leg. 5-1. 
ran continos contemporáneamente y la necesidad de renunciar señala también cierta limitación de la familia a la hora de incluir a más de un miembro entre las filas de los continos del rey. Por contraposición, las familias más destacadas de la oligarquía contarán con más de un miembro entre los continos, especialmente los primogénitos. En 523 el emperador y la reina Juana reciben por contino de su casa a Juan de Herrera, hijo de Jorge de Herrera, también contino, vecino y regidor de Valladolid con una quitación de 50.000 maravedís anuales ${ }^{93}$.

Las renuncias del cargo, la falta de comprobaciones efectivas o incluso la asignación a pesar de no haberse realizado un servicio, muestran una cara del cargo mucho más flexible y que se ajusta más al establecimiento de relaciones duraderas en lugar de puntuales, y con un rasgo clientelar al difuminarse las condiciones del servicio. Esta misma flexibilidad se mostraría en el propio uso que las oligarquías urbanas hicieron del cargo.

\section{CONCLUSIONES}

La flexibilidad y el carácter poliédrico de los continos nos ha permitido acercarnos a ellos desde distintos puntos de vista, de un lado el análisis del cargo de contino como oficio regio, de sus características como precursores de una oficialidad supuestamente más profesionalizada al servicio del Estado moderno, por otro, el cargo de contino desde el punto de vista de aquellos que lo ejercieron y las implicaciones que tuvo en sus carreras o posición social. Es desde estas dos perspectivas desde donde enfocamos nuestras conclusiones.

Al inicio de este artículo hablábamos del tránsito teórico del oficial bajomedieval, en un marco de servicio personal al rey, al tipo de oficial con claras atribuciones y retribuciones que se asocia a la génesis del Estado desde el Renacimiento y a lo largo de la Edad Moderna. Los ejes y datos que hemos ido desgranando muestran una realidad muy diferente. La ruptura de la tendencia inicial a pagar a los continos en función de lo servido parece entrar en directa contradicción con la concepción teleológica de la evolución de la oficialidad. Werner Paravicini parecía entenderlo así cuando, al analizar la corte francesa en los siglos XIV al XV, sugería que las decisiones que el rey tomaba contra las normas que debían regir a los oficiales, iban asimismo en contra de sus deseos y eran resultado de un inevitable sistema de patronazgo que actuaba en contra de los elementos de racionalidad y colegialidad de las instituciones ${ }^{94}$. Sin embargo, si tenemos en cuenta algunas de las tendencias que determinarán los oficios de la Monarquía Hispánica desde finales del siglo XV hasta el XVII (la hereditariedad de los cargos y la venalidad entre otras) identificar

93. AGS, EMR, CONTINOS, Leg. 4.

94. PARAVICINI, Werner: op.cit., p. 177. 
la designación del cliente en lugar del más hábil o la ausencia de una compensación directa por un servicio - una suerte de quid pro quo institucional-, como un rasgo arcaizante solo puede entenderse como resultado de prejuicios weberianos que nublan nuestra comprensión de lo que los oficios públicos significaron durante la Edad Moderna.

Aunque el cargo de contino tuvo una duración limitada y no se prolongó durante la Edad Moderna, su estudio resulta clave, ya que su mayor desarrollo se produjo especialmente durante el reinado de los Reyes Católicos, en un momento fundamental para la definición de los oficios regios. El cargo de contino, por su ductilidad, muestra unas variaciones considerables en las estrategias de designación y las normas a las que los oficiales se ven sujetos. Esta sensibilidad del cargo, no solo es permeable a las necesidades de la Corona, sino que también se va a ir ajustando a los intereses de las oligarquías urbanas y de los servidores regios. El oficio de contino se adapta así a los modelos de compensación o a concepciones patrimoniales y de atribución de un determinado estatus que las élites urbanas ansían. En este sentido, al margen de las estrategias concretas de los distintos individuos y familias ya apuntadas, no hay que olvidar que, además de su valor económico, desde finales del siglo XV el cargo de contino presuponía un estatus y una cercanía a la Corona que complementaba el perfil necesario para formar parte de la élite urbana.

Aunque el acceso al cargo de contino fue una estrategia más entre los recursos utilizados por las distintas familias para fortalecer su estatus de oligarcas en el marco local, también contribuyó, en ocasiones, a desarrollar las carreras individuales de los continos que se veían excluidos de los beneficios de la primogenitura. Un ejemplo lo tenemos en Alonso de Sarabia que, si bien inició su carrera prestando un servicio de carácter militar, llegó a ejercer de corregidor y alcanzar un puesto en la corte como maestresala, aunque finalmente fuera condenado a muerte por su actuación durante las Comunidades.

Asimismo, la ductilidad del oficio permitió a otros continos combinar el servicio regio con su presencia en el ámbito local y obtener un cierto rédito de su cercanía a la Corona.

Este estudio ha demostrado la necesidad de combinar los estudios sobre oficiales regios con la perspectiva local y la documentación regia con la urbana. Solo de esta forma se puede evitar un modelo de monarquía centralista que obvia la perspectiva de los propios oficiales, pero también de los aspirantes a dichos oficios, y del lugar que el oficio adquiere, no solo en la vida del individuo, sino incluso en las estrategias amplias de la familia. Los oficiales no dejan de ser personas radicadas en un contexto urbano, por lo general, e integradas en unas redes sociales oligárquicas y en unas familias que se interesan por consagrar determinados miembros al servicio regio.

Por último, es preciso subrayar que el hecho de que el nombramiento de continos se asimile, en diversa medida según el caso, a modelos de compensación 
a través de mercedes o a nominaciones de corte honorífico, no contradice en absoluto que el de contino sea un verdadero oficio en el sentido premoderno del término. Si el criterio superior para identificar a un oficio como tal es el servicio al bien común -como proponía García Marín en su estudio acerca de los oficios bajo los Austrias- habrá que convenir que la figura de oficial ha de ser por tanto tan plástica como lo era el propio concepto de bien común ${ }^{95}$. Los continos son nombrados como oficiales reales, se comprometen a servir al rey y reciben a cambio una remuneración. Está en el interés tanto de la monarquía como de los propios continos mantener esa relación en una suerte de indefinición que permita variar los servicios y condiciones en función de las necesidades y mantener abiertos distintos canales para potencialmente contentar a ambas partes.

95. García MARín, José María: La burocracia castellana bajo los Austrias. Sevilla, Instituto García Oviedo, Universidad de Sevilla, 1977, p. 79. 


\section{BIBLIOGRAFÍA}

ACHÓN INSAUSTI, José Ángel: «A voz de Concejo»: linaje y corporación urbana en la constitución de la Provincia de Guipuzkoa: los Báñez y Mondragón, siglos XIII-XVI. San Sebastián, Diputación Foral de Gipuzkoa, I995.

AsEnjo GonZÁLEz, María: «Fiscalidad regia y sociedad en los concejos en la Extremadura castellano-oriental durante el reinado de Alfonso X», Homenaje al profesor Juan Torres Fontes. Murcia, Universidad de Murcia, I987, pp. 69-84.

Asenjo González, María: «La aristocratización política en Castilla. El proceso de participación urbana (I252- I520)» en NiETO SoRIA, José Manuel (dir.): La monarquía como conflicto en la corona castellano-leonesa (c. I230-I504). Madrid, Sílex, 2006, pp.I33-196.

Asenjo GonZÁlez, María: «Aristocratic ambitions in oligarchic urban society. Social and political consequences in fifteenth-century castilian towns» en AsENJo GonZÁLEZ, M. (ed.): Urban Elites and Aristocratic Behaviour in the Spanish Kingdoms at the End of the Middle Ages. Turnhout, Brepols, 2013, pp.49-6o.

Bennassar, Bartolomé: Valladolid en el Siglo de Oro. Una ciudad de Castilla y su entorno agrario en el siglo XVI. Valladolid, Ámbito, I989.

Bisson, Thomas N.: La crisis del siglo XII: el poder, la nobleza y los orígenes de la gobernación europea. Barcelona, Crítica, 2010.

Brendecke, Arndt y Martín Romera, M. a Ángeles: «El 'habitus' del oficial real: ideal, percepción y ejercicio del cargo en la monarquía hispánica (siglos XV-XVIII)», Studia Historica. Historia Moderna, 39-I (2017), pp.23-5I.

CARvajAl DE la Vega, David et alii. (eds.): Redes sociales y económicas en el mundo bajomedieval. Valladolid, Castilla Ediciones, 20II.

Dacosta, Arsenio F.: Los linajes de Bizkaia en la Baja Edad Media: poder, parentesco y conflicto. Bilbao, Universidad del País Vasco, 2003.

Descimon, Robert, Schaub, Jean-Frédéric y Vincent, Bernard. (eds.): Les Figures de l'administrateur. Institutions, réseaux, pouvoirs en Espagne, en France et au Portugal, XVIXIX siècle. París, Éditions de l'École des Hautes Études en Sciences Sociales, I997.

Diago Hernando, Máximo: «El papel de los linajes en las estructuras de gobierno urbano en Castilla y en el Imperio alemán durante los siglos bajomedievales», En la España Medieval, 20 (I997), pp. I43-I78.

Diago Hernando, Máximo: «El papel de los corregidores en los conflictos políticos en las ciudades castellanas a comienzos del siglo XVI», En la España medieval, 27 (2004), pp. 195-223.

Esteban Estríngana, Alicia (coord.): Servir al rey en la Monarquía de los Austrias. Medios, fines y logros del servicio al soberano en los siglos XVI y XVII. Madrid, Sílex, 2012.

Gamero IgEA, Germán: «Entre Castilla y Aragón. Los continos en el reinado de Fernando el Católico» en Carvajal, David, Víctores, Imanol, AÑíbarro, Javier. (eds.): Poder, Fisco y Mercado en las ciudades de la Península Ibérica (siglos XIV-XVI). Valladolid, Castilla Ediciones, 2016, pp. 193-208.

García AlcÁZAR, Mª Francisca: «Los continos reales de Castilla durante la baja Edad Media. Estado de la Cuestión», Espacio, Tiempo y Forma, Serie III. Historia Medieval, 30 (20I7), pp. 335-358.

García de VAldeavellano, Luis: Curso de Historia de las instituciones españolas: de los orígenes al final de la Edad Media. Madrid. Alianza, I986 (primera edición I968). 
García Marín, José María: La burocracia castellana bajo los Austrias. Sevilla, Instituto García Oviedo, Universidad de Sevilla, 1977.

García Marín José María: El oficio público en Castilla durante la Baja Edad Media. Alcalá de Henares, Instituto Nacional de Administración Pública, I987.

GonZÁlez Alonso, Benjamín.: El corregidor castellano (I348-I808), Madrid, Instituto de Estudios Administrativos, I970.

GonzÁlez JimÉneZ, Manuel: Alfonso X el Sabio. Barcelona, Ariel, 2004.

LAdERo QuesadA, Miguel Ángel: «Linajes, bandos y parcialidades en la vida política de las ciudades castellanas (Siglos XIV y XV)» en Bandos y querellas dinásticas en España al final de la Edad media / Actas del Coloquio celebrado en la Biblioteca Española de París los días I5 y I6 de mayo de 1987. Madrid, Ministerio de Asuntos Exteriores, Dirección General de Relaciones Culturales, I99I, pp. I05-I34.

Ladero Quesada, Miguel Ángel: «Monarquía y ciudades de realengo en Castilla. Siglos XIl al XV», Anuario de Estudios medievales, 24 (1994), pp.719-774.

Ladero Quesada, Miguel Ángel: La España de los Reyes Católicos, Historia. Madrid, Alianza Editorial, I999.

Мајо Томе́, Beatriz: Valladolid comunera: sociedad y conflictos en Valladolid en el tránsito de la Edad Media a la Moderna. Valladolid, Ayuntamiento de Valladolid, 2017.

Martín Romera, María Ángeles: Las redes sociales de la oligarquía de la villa de Valladolid, (I450-I520), tesis leída en la Universidad Complutense de Madrid, 2012.

Martín Romera, María Ángeles: Redes de poder: las relaciones sociales de la oligarquía de Valladolid (I450-1520). Madrid, CSIC, 2019.

Martínez Millán, José: «De la muerte del príncipe Juan al fallecimiento de Felipe el Hermoso (I497-I506)», en Martínez Millán, J. (Dtor.), La corte de Carlos V. Corte y Gobierno, Vol.I, Madrid, 200o, pp. 45-72.

Martínez Millán, José y EzQuerRa Revilla, Ignacio, «La integración de las elites sociales en las monarquías dinásticas. Los continos» en Bravo Lozano, Jesús (ed.), Espacios de poder: Cortes, ciudades y villas (S. XVI-XVIII). Madrid, J. Bravo, 2002, pp. 339-380.

Molina, José Luis: El análisis de redes sociales. Una introducción. Barcelona, Edicions Bellaterra, 200I.

Monsalvo Antón, José María: «Transformaciones sociales y relaciones de poder en los concejos de frontera, siglos XI-XIII. Aldeanos, vecinos y caballeros en las instituciones municipales« en Reyna Pastor (comp.): Relaciones de poder, de producción y parentesco en la Edad Media y Moderna. Aproximación a su estudio. Madrid, CSIC, I990, pp. Io9-I70.

Monsalvo Antón, José María: «Parentesco y sistema concejil. Observaciones sobre la funcionalidad política de los linajes urbanos en Castilla y León (siglos XIII-XV)». Hispania, 53-I85 (1993), pp. 937-969.

Montero Tejada, Rosa $\mathrm{M}^{\mathrm{a}}$ : «Los continos «hombres de armas» de la Casa Real castellana (I495-I5I6)», Boletín de la Real Academia de la Historia, I98-I (200I), pp.I03-I30.

MonTERo TejAdA, Rosa $\mathrm{M}^{\mathrm{a}}$ : «Monarquía y gobierno concejil: continos reales en las ciudades castellanas a comienzos de la Edad Moderna» en Bernardo AREs, José Manuel (Coord.): La Administración municipal en la Edad Moderna. Actas V Reunión científica de la Asociación Española de Historia Moderna, Vol. 2, Cádiz, I999, pp. 577-590.

PARAVICINI, Werner: «Administrateurs professionnels et princes dilettantes. Remarques sur un problème de sociologie administrative à la fin du moyen âge», en PARAvicinı, Werner y Werner, Karl Ferdinand (eds.): «Histoire comparée de l'administration (IVeXVIII ${ }^{e}$ siècles)». Actes du XIV colloque historique franco-allemand. Tours, 27 mars - I er avril I977. München, Artemis Verlag, I980. 
Pardo Molero, Juan Francisco y Lomas Cortés, Manuel (coords.): Oficiales reales: los ministros de la Monarquía Católica, siglos XVI y XVII. Valencia, Universitat de València, 2012.

Ponce Leiva, Pilar y Andújar Castillo, Francisco (coords.): Mérito, venalidad y corrupción en España y América: siglos XVII y XVIII. Valencia, Albatros, 2016.

RÁbAde Obradó, Ma Pilar: «El doctor Juan Díaz de Alcocer: apuntes biográficos de un servidor de los Reyes Católicos», Espacio, Tiempo y Forma, Serie III, $H^{a}$ Medieval, t. 3 (I990), pp.259-287.

ReINHARD, Wolfgang (comp.): Las élites del poder y la construcción del estado. Madrid, F.C.E. de España, I997.

Requena Santos, Félix: Análisis de redes sociales. Orígenes, teorías y aplicaciones. Madrid, Centro de Investigaciones Sociológicas, Siglo XXI, 2003.

Rodríguez López, Inés: «Continos de Aragón en la empresa colombina» en Armillas Vicente, José Antonio: VII Congreso Internacional de Historia de América: ponencias y comunicaciones (Zaragoza del 2 al 6 de julio de 1996). Zaragoza, Diputación General de Aragón, I998, pp.65I-664.

Rodríguez López, Inés: Los continos de la Casa Real durante el reinado de los Reyes Católicos, (Tesis doctoral inédita), Departamento de Derecho Penal e Historia y Teoría del Derecho, Universidad de Valladolid, 2006.

RucQuor, Adeline: Valladolid en la Edad Media. Valladolid, Junta de Castilla y León, Consejería de Educación y Cultura, I997.

Ruiz Povedano, José María: Poder y sociedad en Málaga: la formación de la oligarquía ciudadana a fines del siglo XV. Málaga, Diputación Provincial de Málaga: Servicio de publicaciones, I989.

Stumpf, Roberta y Chaturvedula, Nandini (coords.): Cargos e ofícios nas monarquias ibéricas: provimento, controlo e venalidade (séculos XVII e XVIII). Lisboa, CHAM, 2012.

SuÁreZ VARELA, Antonio: «La Comunidad de Valladolid y la cuestión conversa: el caso del procurador Alonso de Saravia» en SzÁszdi LEón-Borja, István y GALENDE RuIZ, María Jesús (eds.): Carlos V, conversos y comuneros: 'liber amicorum' Joseph Pérez. Valladolid, 20I5, pp. 259-35I.

SzASZdi León-Borja, István: «Los continos de don Cristóbal Colón», Espacio, Tiempo y Forma, Serie III Historia Medieval, I3 (2000), pp. 397-420.

TOMÁS Y VALIENTE, Francisco: «Origen bajomedieval de la patrimonialización y la enajenación de oficios públicos en Castilla.», Actas del I Symposium de Historia de la Administración. Madrid, I.E.A, I970, pp. I23-160.

VAL VALDivieso, Ma Isabel del: «Ascenso social y lucha por el poder en las ciudades castellanas del siglo XV», En la España Medieval, I7 (I994), pp.I57-I84.

VAL VALDIVIESO, $M^{\mathrm{a}}$ Isabel del: «Aspiraciones y actitudes socio-políticas. Una aproximación a la sociedad urbana de la Castilla bajomedieval» en BonACHíA, Juan Antonio (coord.): La ciudad medieval: Aspectos de la vida urbana en la Castilla bajomedieval. Valladolid, Universidad de Valladolid, I996, pp. 213-254.

VV.AA: Las redes de poder en el mundo contemporáneo, Revista Ayer, I05 (20I7-I).

VV.AA.: Les serviteurs de l'État au Moyen Âge. Actes du XXIXe congrès de la SHMESP (Pau, I998), París, Publications de la Sorbonne, I999.

Weber, Max: Economía y Sociedad. México, FCE, I974. 
Calidad de Revistas

Científicas Españolas

FECYT |
SERIE III HISTORIA MEDIEVAL

REVISTA DE LA FACULTAD DE GEOGRAFÍA E HISTORIA
AÑO 2020

ISSN: 0214-9745

E-ISSN 2340-1362

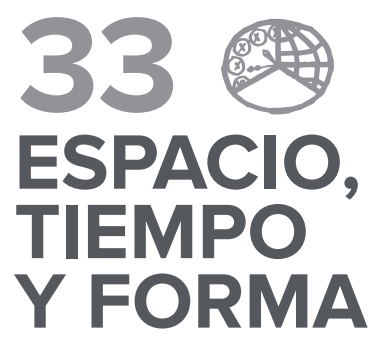

\section{Artículos · Articles}

7 FREDERIC APARISI ROMERO

El cultivo y procesado del lino en el Reino de Valencia (ss. XIII-XVII)

13 ADRIÁN CALONGE MIRANDA

El mantenimiento del entramado viario romano en época medieval en La Rioja. Algunos casos de estudio

\section{Miguel Calleja Puerta}

Notarios públicos entre dos reinos. Apuntes diplomáticos sobre documentos notariales castellanos en el Arquivo Distrital de Braga

\section{Xavier Casassas Canals}

Las 'aqida-s entre los musulmanes castellanos y aragoneses de época mudéjar y morisca: Las 'aqida-s de lbn Abi Zayd Al-Qayrawāni (s. X), Ibn Tümart (s. XII) e Isa de Jebir (s. XV)

\section{ARCADIO DEL CASTILLO}

Sobre el Códice Alcobacense de Vaseo y los Annales Portugalenses Veteres: Continuidad del reino visigodo de Toledo

\section{Paula Castillo}

Las formas de la violencia entre frailes. El testimonio de Fray Ubertino de Casale

\section{María Eugenia CONTRERAS JIMÉnEZ}

La memoria del linaje Arias Dávila en la cofradía y hospital de San Cosme y San Damián de Valladolid (siglos XV a XVII)

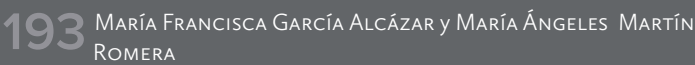
Entre servicio regio y estrategia personal: Los Continos de Valladolid (1480-1525)

\section{César García de Castro Valdés y josé Antonio Valdés
Gallego}

Las inscripciones perdidas de la basílica altomedieval de San Salvador de Oviedo

\section{María José Lop OtÍN}

Hay tal número de clérigos que causa asombro. La clerecía de Toledo a fines de la Edad Media

\section{CORINA LUCHÍA}

Por que los montes de esta villa se conserben, e no se disipen como al presente estan: La regulación de los recursos forestales en la Corona de Castilla (siglos XIV-XVI)
333 María Encarnación Martín López

Las inscripciones medievales del claustro de la catedral de Roda de Isábena (Huesca). Aproximación a su taller lapidario

\section{ISABEL MONTES ROMERO-CAMACHO}

Los archivos catedralicios y su importancia para los estudios prosopográficos. El deán Don Aparicio Sánchez, en el Archivo de la Catedral de Sevilla

\subsection{Gonzalo Oliva Manso}

La moneda en Castilla y León (1265-1284). Alfonso X, un adelantado a su tiempo.

4.73 Mariana Valeria Parma

Entre los signos del cielo y las voces de los hombres: La visión medieval del cielo y su representación apocalíptica

\section{Milagros Plaza Pedroche \\ Los maestres santiaguistas y su designación regia durante el} reinado de Juan I de Trastámara (1379-1390): La legitimación del proceso

521 Juan A. Prieto Sayagués

La profesión de las élites castellanas en los monasterios y conventos durante la Baja Edad Media

\section{ENRIQUE JOSÉ RUIZ PILARES}

La funcionalidad social de los inmuebles urbanos de las élites dirigentes bajomedievales: Reflexiones a partir de un caso de estudio (Jerez de la Frontera, España)

\section{Gilberto SORIANO Calvo}

Influencia de las redes nobiliarias en la expansión cristiana del siglo XII. El caso de Soria

Mohammed S. TawfiQ, AlmudenaArizaArmada, Atef Mansour Mohammad, Ahmed Ameen y Mervat Abd EL-HadyAbdEL-Latif A Historical and Numismatic Study of the Dinars of the Ghaznavid Sultan Mahmūd B. Sabuktakin at Nishapur

653 JOSÉ LUIS DE VILLAR IGLESIAS

Los aspectos económicos en la Batalla por el Magreb entre omeyas y fātimíes: El control del acceso al oro del Sudán Occidental 


\section{3}

\section{ESPACIO,}

\section{TIEMPO}

Y FORMA

UกED

SERIE III HISTORIA MEDIEVAL

REVISTA DE LA FACULTAD DE GEOGRAFİA E HISTORIA

\section{Libros · Books}

679 Bello León, Juan Manuel y ORTEgo Rico, Pablo, Los agentes fiscales en la Andalucía Atlántica a finales de la Edad Media: Materiales de trabajo y propuesta de estudio (ANA MARÍA RIVERA MEDINA)

683 Calleja Puerta, Miguel y Domínguez Guerrero, María Luisa (eds.), Escritura, notariado y espacio urbano en la Corona de Castilla y Portugal (siglos XII-XVII) (PALOMA CUENCA MuÑoz)

687 CASADO Alonso, Hilario (coord.), Comercio, finanzas $y$ fiscalidad en Castilla (siglos XV-XVI) (ANA MARía RIVERA MEdINA)

691 Castro Correa, Ainoa y Rodríguez Sánchez, Manuel, Colección diplomática altomedieval de Galicia II. Documentación en escritura visigótica de la sede lucense (PALOMA CUENCA MUÑOZ)

695 García Fernández, Ernesto, García-Gómez, Ismael, Rodríguez FERNÁNDEZ, José, Urbanismo, patrimonio, riqueza y poder en Vitoria-Gasteiz a fines de la Edad Media e inicios de la Edad Moderna (ENRIQUE CANTERA MONTENEGRO)

699 LADERO QUESADA, Miguel Ángel, Ciudades de la España medieval. Introducción a su estudio (GISELA CORONADO SCHWINDT)

705 LADERo Quesada, Miguel Ángel, Los últimos años de Fernando el Católico 1505-1517 (CARlos Barquero GoÑI)

707 Martín GutiérRez, Emilio y Ruiz Pilares, Enrique José, El viñedo en Jerez durante el siglo XV. Un mercado de trabajo en torno al vino (ANa María Rivera MEDINA)

711 MONSALVO ANTÓN, José María, La construcción del poder real en la monarquía castellana (siglos XI-XV) (MARÍA JeSÚs FUENTE)

715 Pérez Rodríguez, Francisco Javier, Los monasterios del Reino de Galicia entre 1075 y 1540: De la reforma gregoriana a la observante (EnRIQue Cantera Montenegro)

717 REIXACH SALA, Albert, Finances públiques i mobilitat social a la Catalunya de la Baixa Edat Mitjana. Girona, 1340-1440 (JuLIÁN DONADO VARA)

721 SÁNCHEZ SÁNCHEZ, Xosé M., Iglesia, mentalidad y vida cotidiana en la Compostela medieval (ENRIQUe CANTERA MONTENEGRO)

725 Val Valdivieso, M. ${ }^{a}$ Isabel del, Martín Cea y Juan Carlos, CARVAJAL de La Vega, David (coords.), Expresiones del poder en la Edad Media. Homenaje al profesor Juan Antonio Bonachía Hernando (José RAMÓN DÍAZ DE DURANA ORTIZ DE URBINA) 